\title{
High-Resolution Biomass Burning Aerosol Transport Simulations in the Tropics
}

\author{
Nurzahziani ${ }^{1}$, Chinnawat Surussavadee ${ }^{2,3, *}$ (D) and Thanchanok Noosook ${ }^{1}$ \\ 1 Interdisciplinary Graduate School of Earth System Science and Andaman Natural Disaster Management, \\ Prince of Songkla University, Phuket Campus, Phuket 83120, Thailand; zahziani@yahoo.co.id (N.); \\ parn.4th@gmail.com (T.N.) \\ 2 CPS Weather Company Limited, Bangkok 10250, Thailand \\ 3 Research Laboratory of Electronics, Massachusetts Institute of Technology, Cambridge, MA 02139, USA \\ * Correspondence: pop@alum.mit.edu; Tel.: +66-84-840-0090
}

Received: 29 November 2019; Accepted: 8 January 2020; Published: 12 January 2020

check for updates

\begin{abstract}
This study evaluates the performance of the Weather Research and Forecasting Model with Chemistry (WRF-Chem) for simulating biomass burning aerosol transport at high resolution in the tropics using two different biomass burning emission inventories. Hourly, daily, and monthly average PM10 dry mass concentrations at $5 \mathrm{~km}$ resolution—simulated separately using the Brazilian Biomass Burning Emission Model (WRF-3BEM) and the Fire Inventory from NCAR (WRF-FINN) and their averages (WRF-AVG) for 3 months from February to April-are evaluated, using measurements from ground stations distributed in northern Thailand for 2014 and 2015. Results show that WRF-3BEM agrees well with observations and performs much better than WRF-FINN and WRF-AVG. WRF-3BEM simulations are almost unbiased, while those of WRF-FINN and WRF-AVG are significantly overestimated due to significant overestimates of FINN emissions. WRF-3BEM and the measured monthly average PM10 concentrations for all stations and both years are 89.22 and $87.20 \mathrm{\mu} \mathrm{m}^{-3}$, respectively. The root mean squared error of WRF-3BEM simulated monthly average PM10 concentrations is 72.00 and $47.01 \%$ less than those of WRF-FINN and WRF-AVG, respectively. The correlation coefficient of WRF-3BEM simulated monthly PM10 concentrations and measurements is 0.89 . WRF-3BEM can provide useful biomass burning aerosol transport simulations for the northern region of Thailand.
\end{abstract}

Keywords: air quality modeling; biomass burning emissions; biomass burning aerosol transport simulation; northern region of Thailand; PM10 concentration; smoke haze episode

\section{Introduction}

Thailand is an agricultural country, where nearly half of all Thai workforce is in the agricultural sector. Biomass burning is the main cause for the smoke haze episode covering a large area of the northern region of Thailand in every cold season. Biomass burning in the region is mainly related to agricultural activities. Open biomass burning occurs both before harvesting to facilitate harvesting operations, and after harvesting to get rid of crop residues in preparation for a new planting season. Most forest fires are mainly caused by human activities [1]. Burning crop residues in agricultural industries-e.g., the sugarcane industry—is also a main cause of biomass burning.

Particulate matters (PMs), which are generated by biomass burning, severely degrade air quality and greatly impact public health and visibility in many provinces in the northern region of Thailand. During the smoke haze episodes, the number of patients with respiratory diseases was found to significantly increase [2]. Due to the important impacts of PM to the public, the capability to provide 
three-dimensional maps of PM transport as a function of time is important for developing a more detailed understanding and solving the problem.

Ground stations can provide measured PM dry mass concentrations at specific locations. However, they are sparse and cannot provide detailed information about the PM spatial distribution and transport and their sources. Even though satellite observations can provide information about the PM spatial distribution and transport, they are often obstructed by clouds. A high-resolution numerical aerosol transport simulation system is the only method that can provide three-dimensional maps of biomass burning emissions of particles and trace gases as a function of time.

Several previous studies have employed numerical models for aerosol transport simulations [3-6]. Since different numerical models have been developed differently, they perform differently for different areas. It has also been shown that employing the same numerical model for the same study area but with different global biomass burning emissions inventories leads to different results $[7,8]$. Moreover, atmospheric parameters related to aerosol transport are inhomogeneous, particularly for the area in the tropics with complex terrain [9]. Since the northern region of Thailand is in the tropics and has complex terrain, a numerical model that can provide biomass burning aerosol transport simulations at high resolution is required.

Despite the crucial need of a useful high-resolution numerical aerosol transport simulation system for the northern region of Thailand, only a few previous studies exist. Biomass burning aerosol transport in the northern region of Thailand has been simulated using a system composed of the next-generation Weather Research and Forecasting Model (WRF) and the California Puff Mesoscale Dispersion Model (CALPUFF) [10]. However, the resolution of the simulations is only at $12 \mathrm{~km}$, the study area only covers a single province, i.e., Chiang Mai, the study period is only in a single month, i.e., March 2007, and only measurements from two ground stations are used for evaluating the simulated daily average concentrations of particulate matters less than $10 \mu \mathrm{m}$ (PM10). Biomass burning aerosol transport in upper Southeast Asia, which includes the northern region of Thailand, in March 2012 simulated using a system composed of the Weather Research and Forecasting Model (WRF) and the Community Multiscale Air Quality (CMAQ) model has been assessed in [8]. PM10 concentrations simulated using two different global fire emission inventories, i.e., the Fire INventory from NCAR (FINN) and the Global Fire Assimilation System (GFAS), are evaluated using measurements from 13 ground stations, which are the same ground stations employed in this study, with the addition of the Tap Mun station located in Hong Kong. Results show that monthly average PM10 concentrations simulated using FINN and GFAS are not only very different among themselves, but they are also very different from ground measurements, that is, monthly average PM10 concentrations simulated using FINN and GFAS and measurements are 312, 79, and $143 \mu \mathrm{g} \mathrm{m}^{-3}$, respectively. While FINN PM10 concentration simulations are significantly overestimated, GFAS simulations are significantly underestimated. In addition, the resolution of the simulations is only at $27 \mathrm{~km}$.

This study is the work towards the main goal of developing a high-resolution numerical aerosol transport simulation system that can provide useful high-resolution aerosol transport simulations for the northern region of Thailand. Although our preliminary study [11] has evaluated high-resolution numerical aerosol transport simulations for the northern region of Thailand, it only employs one biomass burning emission inventory, i.e., the Brazilian Biomass Burning Emission Model (3BEM) [12], and only evaluates simulated hourly average PM10 concentrations in 2015.

The Weather Research and Forecasting Model with Chemistry (WRF-Chem) has been widely used for air quality modeling studies [3-6,13-15]. WRF-Chem is employed in this study. Biomass burning emissions from two inventories, including 3BEM and the Fire Inventory from NCAR version 1.5 (FINN) [16] are employed. The study area covers the whole of the northern region of Thailand. Hourly, daily, and monthly average PM10 dry mass concentrations at $5 \mathrm{~km}$ resolution simulated using 3BEM and FINN for the 3-month period, which covers when PM10 concentrations are peak, are evaluated using measurements from 12 and 13 ground stations distributed in the northern region 
of Thailand in years 2014 and 2015, respectively. The averages of 3BEM and FINN simulated PM10 concentrations are also evaluated.

Section 2 describes the research methodology employed in this study, which includes the study area, measurements of PM10 dry mass concentrations from ground stations, WRF-Chem domain configurations, biomass burning emission inventories employed in this study, and evaluation method. The evaluation results are presented in Section 3. Section 4 summarizes and concludes this study.

\section{Research Methodology}

\subsection{Study Area}

The study area covers the northern region of Thailand and is shown in the red box in Figure 1a. Thailand is located in the center of the Indochina peninsula and is bordered by Myanmar and Laos to the north, Laos and Cambodia to the east, the Gulf of Thailand and Malaysia to the south, and the Andaman Sea and the southern extremity of Myanmar to the west. The weather in Thailand is tropical and is mostly hot and humid. There are three seasons, including the cold season (approximately from the middle of October to the middle of February), the hot season (approximately from the middle of February to the middle of May), and the rainy season (approximately from the middle of May to the middle of October). The southwest and northeast monsoons strongly drive the weather in Thailand [17]. The southwest monsoon occurs from approximately the middle of May to the middle of October and brings humid air from the Indian Ocean to the west of Thailand, which leads to the rainy season. The northeast monsoon occurs approximately from the middle of October to the middle of February and brings the cold and dry air to the northern and northeastern parts of Thailand, which leads to the cold season. The northeast monsoon also brings humid air from the Gulf of Thailand to the eastern part of Thailand's southern peninsula.

Figure $1 \mathrm{~b}$ zooms in the study area of this study. It covers the whole of the northern region of Thailand, where terrain is complex with high mountains. Since the land in the region is fertile, agriculture is widespread. The smoke haze problem usually occurs in the dry season and affects the air quality of all provinces in the region. To see the temporal distribution and density of hotspots in the study area, Figure 2 shows all hotspot locations shown by red dots occurring in February-May of 2014 from the Collection 6 Terra/Aqua Moderate Resolution Imaging Spectroradiometer (MODIS) fire products $[18,19]$. Hotspots are widespread in the study area and surrounding regions with high densities in March and April. The hotspot locations and densities occurring in 2015 are similar to those occurring in 2014. The hotspot data are not directly used in any computations in this study. The biomass burning emission data employed in this study is from the inventories described later in Section 2.4. 


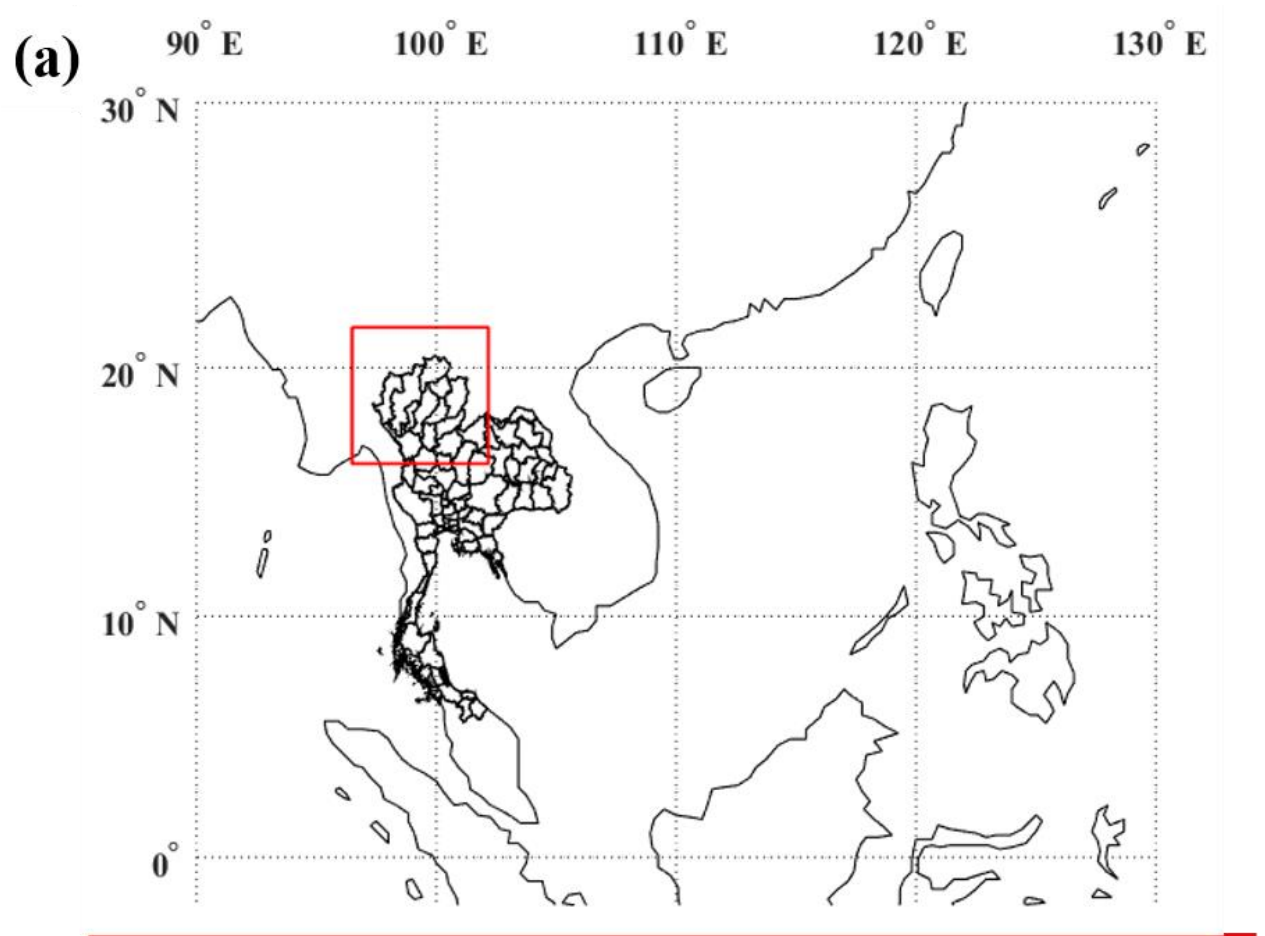

(b)

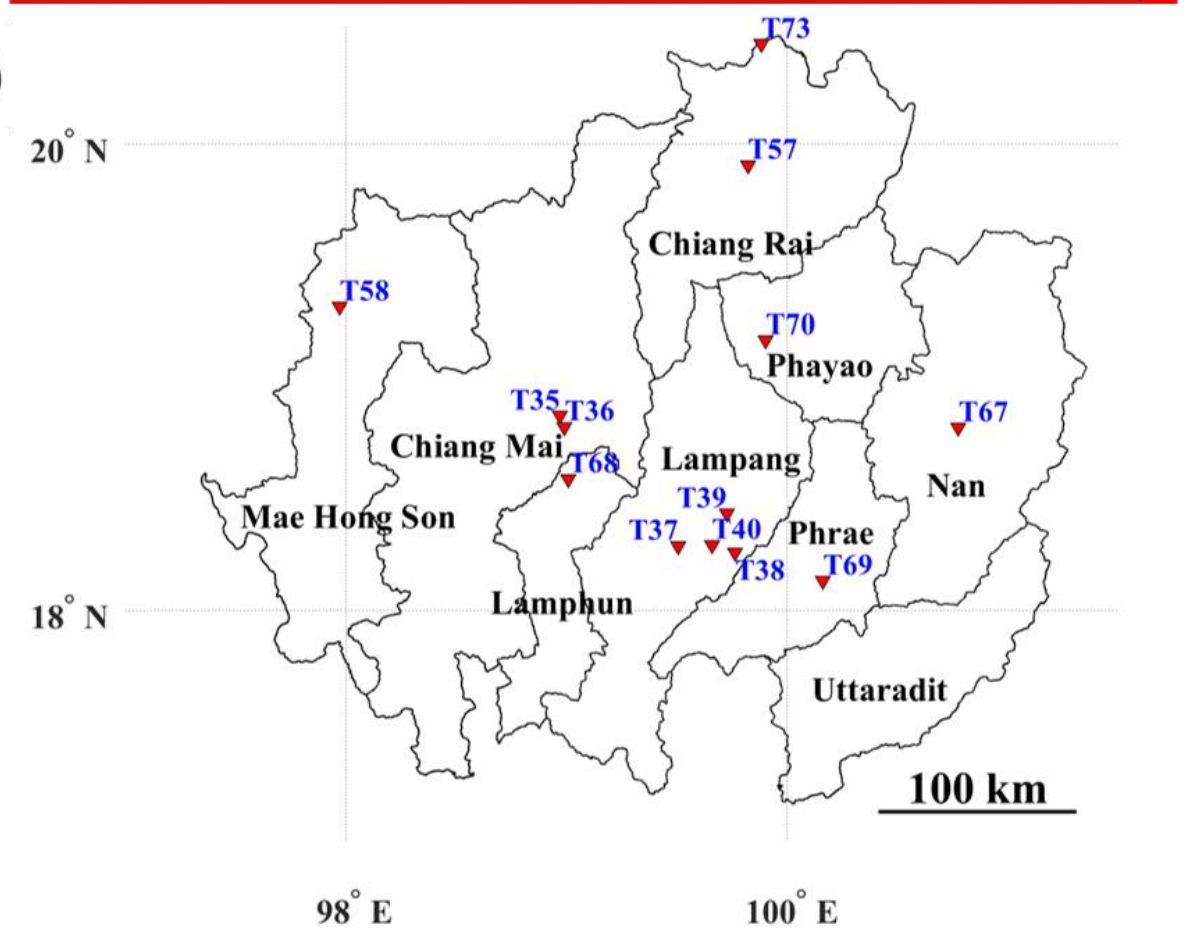

Figure 1. (a) Overview of the study area, which is in the red box. (b) Locations of 13 PM10 concentration measuring stations in the northern region of Thailand employed in this study, where black lines show boundaries of provinces. 

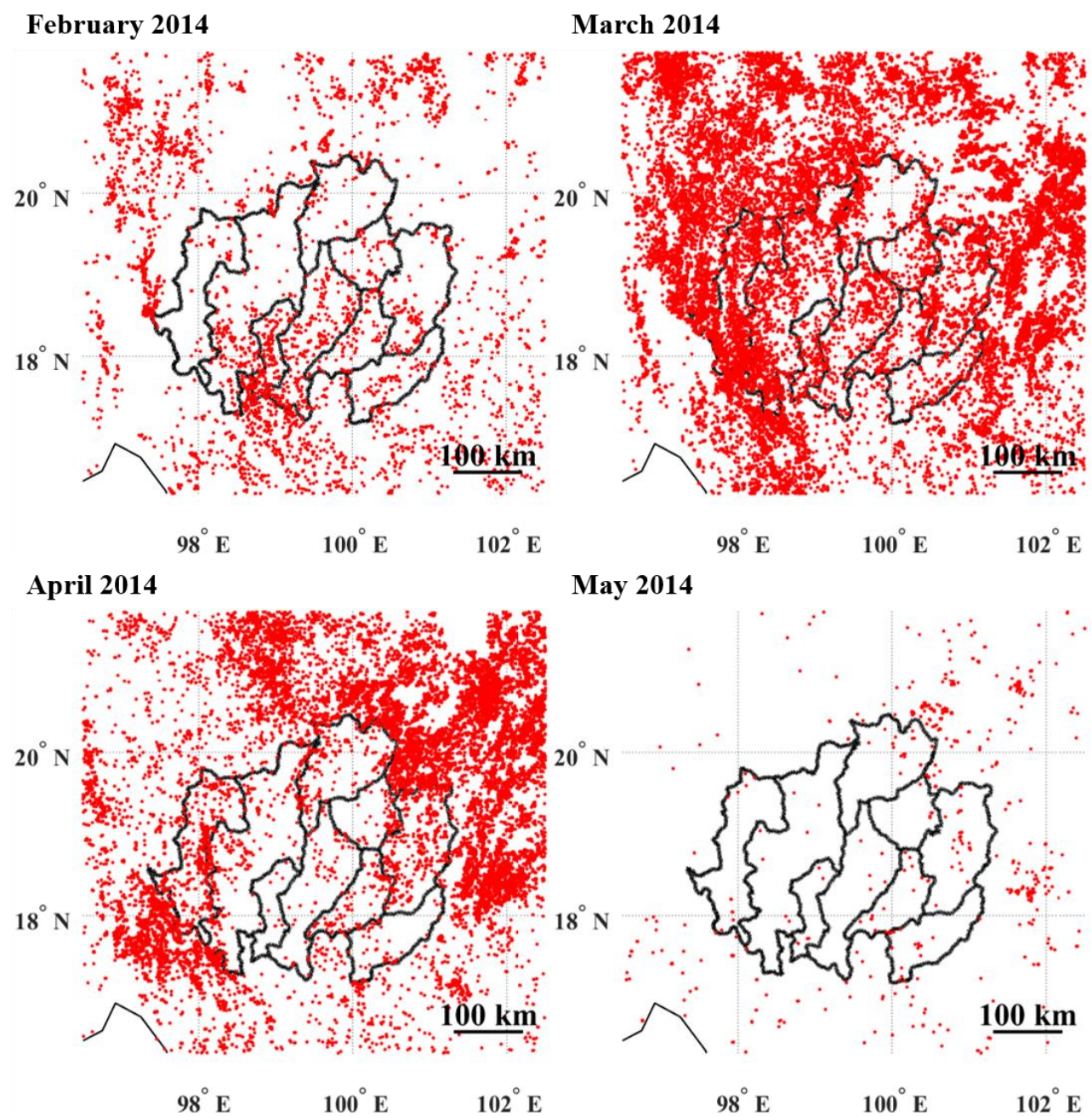

May 2014

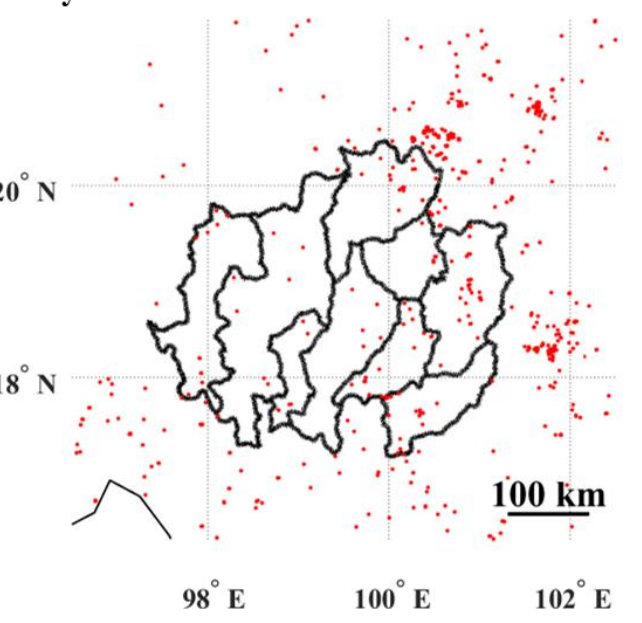

Figure 2. All hotspots occurring in February-May of 2014 in the study area and neighboring regions.

\subsection{Measurements of PM10 Dry Mass Concentrations from Ground Stations}

The measurements of PM10 dry mass concentrations employed in this study are from 13 ground stations that are distributed in the northern region of Thailand and are operated by the Thailand Pollution Control Department. The locations of the 13 stations are shown in Figure 1b. Table 1 shows the latitude, longitude, province, land use category, topography $(\mathrm{m})$ above mean sea level, dates when the peak daily average PM10 concentrations occurred in 2014 and 2015, and the peak values of daily average PM10 concentrations for both years for the 13 ground stations. Two stations, i.e., T35 and T36, are in Chiang Mai. Four stations, i.e., T37, T38, T40, and T57 are in Lampang, two stations, i.e., T57 and T73, are in Chiang Rai. Five other stations are in Mae Hong Son, Nan, Lamphun, Phrae, and Phayao. T73 is the most northern station, while T69 is the most southern station. T58 is the most western station, while T67 is the most eastern station. The land use category for most stations is urban. The land use data shown in Table 1 is from the Thailand Land Development Department and is at $15 \mathrm{~m}$ resolution. 
Table 1. Latitude, longitude, province, land use category, topography ( $\mathrm{m}$ ) above mean sea level, dates when the peak daily average PM10 concentrations occurred in 2014 and 2015, and the peak daily average PM10 concentrations for both years for the 13 ground stations.

\begin{tabular}{|c|c|c|c|c|c|c|c|c|c|}
\hline \multirow{3}{*}{ Station } & \multirow{3}{*}{ Latitude } & \multirow{3}{*}{ Longitude } & \multirow{3}{*}{ Province } & \multirow{3}{*}{$\begin{array}{l}\text { Land Use } \\
\text { Category }\end{array}$} & \multirow{3}{*}{$\underset{\text { (m) }}{\text { Topography }}$} & \multicolumn{4}{|c|}{$\begin{array}{c}\text { Peak of Daily Average PM10 } \\
\text { Concentration }\end{array}$} \\
\hline & & & & & & \multicolumn{2}{|c|}{ Month/Date } & \multicolumn{2}{|c|}{ Values $\left(\mu \mathrm{g} \mathrm{m}^{-3}\right)$} \\
\hline & & & & & & 2014 & 2015 & 2014 & 2015 \\
\hline T35 & 18.8406 & 98.9697 & Chiang Mai & Urban & 410.7 & $3 / 21$ & $3 / 16$ & 284.0 & 282.4 \\
\hline Т36 & 18.7911 & 98.9900 & Chiang Mai & Urban & 365.4 & $3 / 21$ & $3 / 16$ & 240.0 & 299.8 \\
\hline $\mathrm{T} 37$ & 18.2783 & 99.5064 & Lampang & Urban & 274.2 & $3 / 7$ & $3 / 12$ & 204.3 & 213.2 \\
\hline $\mathrm{T} 38$ & 18.2507 & 99.7640 & Lampang & Urban & 395.2 & $3 / 7$ & $3 / 12$ & 181.5 & 165.0 \\
\hline T39 & 18.4197 & 99.7273 & Lampang & Agriculture & 409.5 & N/A & $3 / 1$ & $\mathrm{~N} / \mathrm{A}$ & 255.3 \\
\hline $\mathrm{T} 40$ & 18.2827 & 99.6599 & Lampang & Forest & 377.15 & $3 / 10$ & $3 / 1$ & 138.7 & 260.0 \\
\hline T57 & 19.9092 & 99.8234 & Chiang Rai & Urban & 381.4 & $3 / 21$ & $3 / 17$ & 263.3 & 384.0 \\
\hline T58 & 19.3047 & 97.9710 & $\begin{array}{l}\text { Mae Hong } \\
\text { Son }\end{array}$ & Urban & 410.7 & $3 / 21$ & $3 / 15$ & 322.7 & 304.0 \\
\hline T67 & 18.7889 & 100.7764 & Nan & Urban & 224.6 & $3 / 3$ & $3 / 16$ & 169.7 & 189.2 \\
\hline T68 & 18.5674 & 99.0080 & Lamphun & Urban & 287.75 & $3 / 21$ & $3 / 17$ & 175.6 & 218.2 \\
\hline T69 & 18.1289 & 100.1623 & Phrae & Urban & 183.7 & $3 / 6$ & $3 / 1$ & 181.2 & 214.7 \\
\hline T70 & 19.1639 & 99.9027 & Phayao & Urban & 385.85 & $3 / 7$ & $3 / 16$ & 211.0 & 263.5 \\
\hline T73 & 20.4272 & 99.8837 & Chiang Rai & Urban & 510.9 & $3 / 20$ & $3 / 18$ & 244.9 & 282.6 \\
\hline
\end{tabular}

Figure 3 shows the time series of measured hourly averaged PM10 dry mass concentrations covering the whole years of 2014 and 2015 for 13 stations employed in this study. The smoke haze episode occurred during February-April of each year, where PM10 concentrations for these stations peak in March. The peak of PM10 concentration in March is consistent with the highest density of hotspots that occur in March, as Figure 2 shows. The smoke haze affects all stations with different magnitudes and times. The station T58 in Mae Hong Son has the highest hourly average PM10 concentrations for both years, where the peak hourly average PM10 concentrations are 593 and $660 \mu \mathrm{g} \mathrm{m}^{-3}$, in 2014 and 2015, respectively. Since the station T39 does not have measurements during February-April of 2014, it is not employed in this study for 2014.

Table 1 shows that the peak daily average PM10 concentrations for both years for all stations occurred in March. The highest daily average PM10 concentration in 2014 occurred at the station T58 in Mae Hong Son on 21 March with the value of $322.7 \mu \mathrm{g} \mathrm{m}^{-3}$. The highest daily average PM10 concentration in 2015 occurred at the station T57 in Chiang Rai on 17 March with the value of $384.0 \mu \mathrm{g} \mathrm{m}^{-3}$. The peak daily average PM10 concentrations for most stations for both years significantly exceed the safety standards set by World Health Organization (WHO) and Thailand Pollution Control Department and, which are 50 and $120 \mu \mathrm{g} \mathrm{m}^{-3}$, respectively $[20,21]$. This emphasizes the need for this study.

\subsection{WRF-Chem Domain Configurations}

The Weather Research and Forecasting Model (WRF) is the state-of-the-art mesoscale numerical weather prediction system widely used for atmospheric research and operations [22]. The research in [23] has shown that WRF can provide high-resolution weather forecasts in good agreement with satellite observations for Thailand and nearby regions. The research in [24,25] has also shown that WRF can provide simulated and forecasted near surface wind speed and direction in good agreement with measurements. WRF has several versions and has two dynamical solvers, i.e., the Advanced Research WRF (ARW) core and the Nonhydrostatic Mesoscale Model core. The WRF model with Chemistry (WRF-Chem) is a version of the WRF model that simultaneously simulates the emission transport, turbulent mixing, and chemical transformation of trace gases and aerosols with the meteorology [26,27]. The WRF-Chem version 3.5.1 with the ARW dynamical solver is employed in this study. 

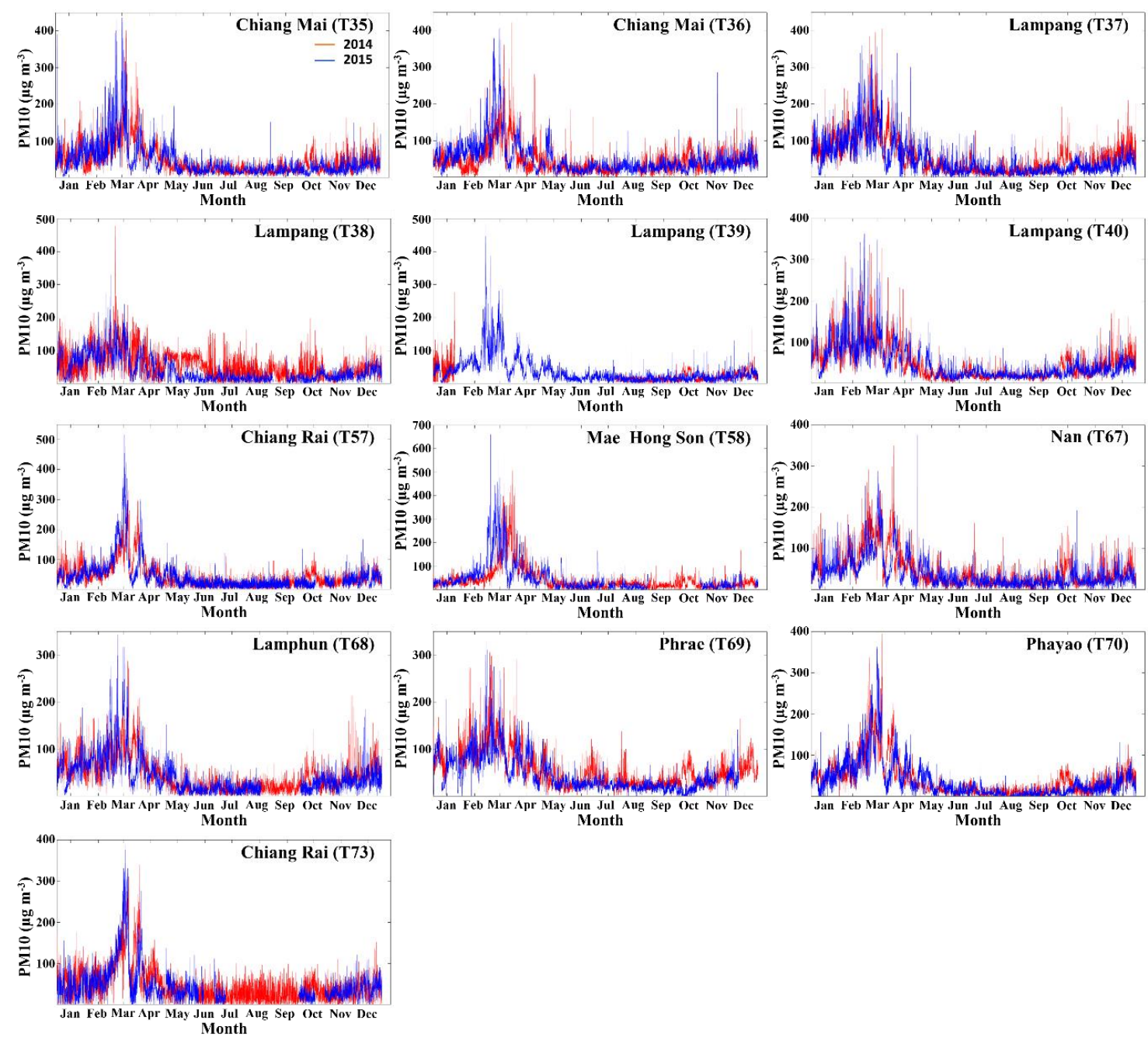

Figure 3. Time series of measured hourly average PM10 concentrations $\left(\mu \mathrm{g} \mathrm{m}^{-3}\right)$ covering the whole years of 2014 (red) and 2015 (blue) for 13 stations employed in this study.

Table 2 shows WRF-Chem domain configurations and physics options employed in this study. This study employs two nested domains co-centered at $18.97^{\circ} \mathrm{N}$ and $99.4^{\circ} \mathrm{E}$, as Figure 4 a shows. The inner domain is chosen to focus on the northern region of Thailand. The outer domain is chosen to be large enough to cover hot spots whose emissions could transport into the inner domain. The outer domain has $99 \times 99$ grid points at $15 \mathrm{~km}$ resolution. The inner domain has $120 \times 120$ grid points at $5 \mathrm{~km}$ resolution. Both domains have 45 terrain-following vertical levels extending from the surface to $50 \mathrm{mb}$. Since this study focuses on PM10 near surface, vertical levels are selected to have high resolution near surface. There are 6 terrain-following levels that are below the planetary boundary layer (PBL). The height of PBL varies with time. The average altitudes above ground for the five lowest terrain-following levels above ground are 4.15, 8.29, 16.60, 24.92, and $33.25 \mathrm{~m}$. Outputs from the inner domain at $5 \mathrm{~km}$ resolution are used for evaluation. Figure $4 \mathrm{~b}$ shows topography above mean sea level of the inner domain. The terrain of the study is complex with high mountains in the west, north, and east and low flat land in the south. The topographic data employed in this study is the U.S. Geological Survey (USGS) data at 30 arcsecond resolution. The USGS-based land use data with 24 categories at 30 arcsecond resolution is employed in this study. Since the resolution of the simulations in this study is $5 \mathrm{~km}$, the resolutions of the topographic and land use data employed in this study are appropriate. 
Table 2. WRF-Chem domain configurations and physics options employed in this study.

\begin{tabular}{|c|c|c|}
\hline Configuration & Domain 1 & Domain 2 \\
\hline Grid Size & $99 \times 99$ & $120 \times 120$ \\
\hline Spatial Resolution (km) & 15 & 5 \\
\hline Number of Vertical Levels & 45 & 45 \\
\hline Microphysics Scheme & WRF Double-Moment 6-class & WRF Double-Moment 6-class \\
\hline $\begin{array}{l}\text { Cumulus Parameterization } \\
\text { Scheme }\end{array}$ & Grell 3D Ensemble Scheme & Grell 3D Ensemble Scheme \\
\hline $\begin{array}{l}\text { Planetary Boundary Layer (PBL) } \\
\text { scheme }\end{array}$ & Bretherton and Park & Bretherton and Park \\
\hline Surface Layer Scheme & Revised MM5 Monin-Obukhov & Revised MM5 Monin-Obukhov \\
\hline Land Surface Model & Unified Noah & Unified Noah \\
\hline Aerosol Scheme & $\begin{array}{c}\text { Goddard Chemistry Aerosol } \\
\text { Radiation and Transport }\end{array}$ & $\begin{array}{l}\text { Goddard Chemistry Aerosol } \\
\text { Radiation and Transport }\end{array}$ \\
\hline
\end{tabular}

(a)

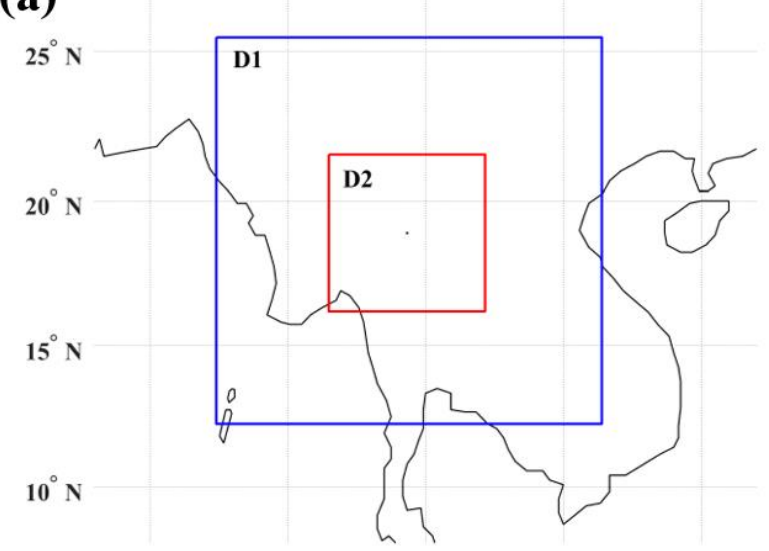

$90^{\circ} \mathrm{E} \quad 95^{\circ} \mathrm{E} \quad 100^{\circ} \mathrm{E} \quad 105^{\circ} \mathrm{E} \quad 110^{\circ} \mathrm{E}$

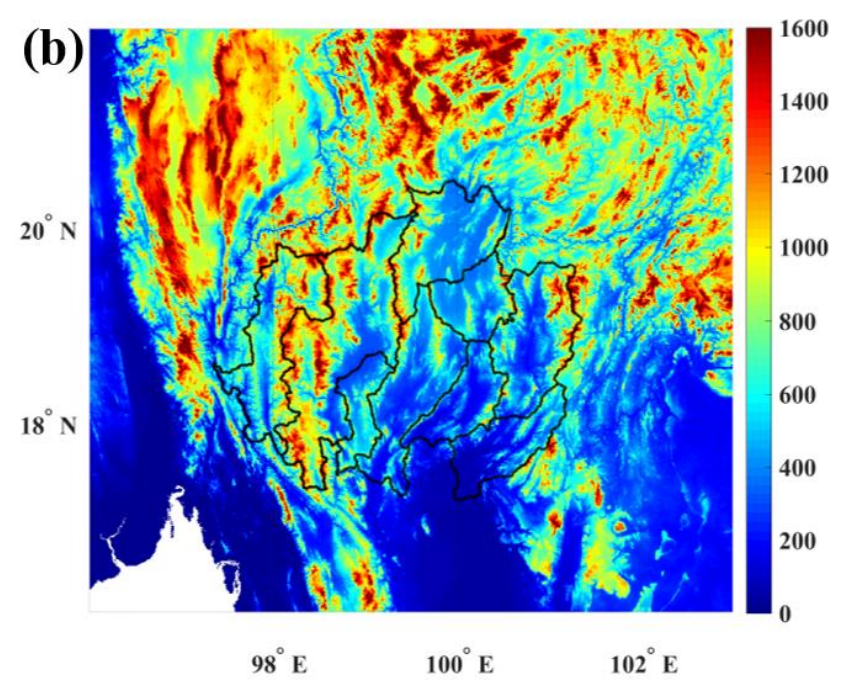

Figure 4. (a) Coverages of two nested WRF domains employed in this study. (b) Topography (m) above mean sea level of WRF domain 2.

WRF provides many physics options for users to choose for each parameter and domain. The WRF Double-Moment 6-class microphysics scheme [28] and the Grell 3D Ensemble Scheme 
cumulus parameterization scheme [29] are employed for both domains. Previous studies [30-32] have demonstrated that the activation of the cumulus parameterization scheme in the inner domain with high resolution improves the precipitation simulations. Since this study focuses on PM10 concentrations near the ground, the performance of the model for simulating near-surface wind fields is important. The research in $[24,25]$ has evaluated WRF planetary boundary layer (PBL) schemes for simulating near-surface winds in northeastern Thailand and found that the Bretherton and Park (UW) PBL scheme [33] together with the Revised MM5 Monin-Obukhov surface layer scheme [34] and the Unified Noah land surface model [35] provides the best agreement between simulations and measured wind speed and direction. They are employed in this study for both domains.

The NCEP final operational model global tropospheric analyses on a 1-degree grid available every $6 \mathrm{~h}$, i.e., $00,06,12$, and $18 \mathrm{Z}$, from the surface to $10 \mathrm{mb}$ are used as initial and boundary conditions for WRF. The NCEP analyses have successfully been employed by [36] to simulate 122 global storm systems at $5 \mathrm{~km}$ resolution with good agreement with coincident satellite passive millimeter-wave observations. Data assimilation techniques and nudging are not employed in this study.

The chemical part of WRF-Chem employs the Goddard Chemistry Aerosol Radiation and Transport (GOCART) aerosol scheme [37]. The preprocessor PREP-CHEM-SRC version 1.5 [38] is employed to prepare emission fields of trace gases and aerosols for WRF-Chem. Both anthropogenic emission and biomass burning emission are included, where details about the biomass burning emission inventories employed in this study are described in the next section. The anthropogenic emission data from two emission inventories, including the REanalysis of the TROpospheric chemical composition over the past 40 years (RETRO) [39] and the Emission Database for Global Atmospheric Research version 4 (EDGARv4) [40] are employed. The RETRO global emission data is based on the year 2000 and is at 0.5 degree resolution. The EDGARv4 global emission data is based on the year 2005 and is at 0.1 degree resolution. Emissions of organic carbon, black carbon, sulfur dioxide $\left(\mathrm{SO}_{2}\right)$, and dimethylsulfide (DMS) based on the year 2006 at 1 degree resolution from the GOCART model database are employed.

\subsection{Biomass Burning Emission Inventories Employed in This Study}

Several inventories of global biomass burning emissions are available to be used [12,16,41,42]. In this study, biomass burning emissions from the Brazilian Biomass Burning Emission Model (3BEM) [12] and the Fire Inventory from NCAR version 1.5 (FINN) [16] are employed and their simulation results are compared.

3BEM provides daily global estimates of trace gases and particle emissions from biomass burning at $1 \mathrm{~km}$ resolution. 3BEM estimates biomass burning emissions for each detected fire pixel using

$$
M_{i}=L \cdot \times C \times \cdot F_{i} \times A
$$

where $M_{i}$ is the emission load of species $i$ (mass of $i$ emitted; $g$ ), $L$ is the biomass loading $\left(\mathrm{kg} \mathrm{km}^{-2}\right), C$ is the combustion factor (the fraction of that biomass burned in in the fire; unitless), $F_{i}$ is the emission factor for a certain species $i$ (mass of $i$ emitted divided by mas of biomass burned; $\mathrm{g} \mathrm{kg}^{-1}$ ), and $A$ is the burned area $\left(\mathrm{km}^{2}\right)$. To detect the actively hotspot locations, 3BEM employs the combination of satellite observation products, including: (1) the Wildfire Automated Biomass Burning Algorithm (WF_ABBA) product using observations from the Geostationary Operational Environmental Satellite (GOES) constellation data [43], (2) the Brazilian National Institute for Space Research (INPE) fire product using observations from the Spinning Enhanced Visible and Infrared Imager (SEVIRI) onboard Meteosat Second Generation, the Advanced Very High Resolution Radiometer (AVHRR) aboard the National Oceanic and Atmospheric Administration (NOAA) constellation, GOES, and MODIS [44], and (3) the MOD14 and MYD14 products using observations from MODIS aboard the Terra and Aqua satellites [18]. To avoid counting the same fire more than once in each day, the three products are combined by eliminating multiple detections of the same fire location within a circle of $1 \mathrm{~km}$ radius. 
The emission factor $\left(F_{i}\right)$, the combustion factor $(C)$, and the biomass loading $(L)$ are estimated using the MODIS land cover map at $1 \mathrm{~km}$ resolution, where values from literatures are employed [12].

FINN provides daily global estimates of trace gases and particle emissions from open biomass burning at $1 \mathrm{~km}$ resolution. While FINN includes wildfire and agricultural fires, it does not include biofuel use and trash burning. FINN also estimates biomass burning emissions for each detected fire pixel using Equation (1). The locations of active fires are from the MOD14 and MYD14 products using observations from MODIS aboard the Terra and Aqua satellites. Since MODIS does not observe the entire globe daily due to its swath width—its detected active fires over two days are smeared to generate daily FINN estimates. To avoid counting the same fire more than once in a single day, multiple detections of the same fire location for each day are removed. The emission factor, the combustion factor, and the biomass loading (L) are estimated using the MODIS Land Cover Type for 2005 and the MODIS Vegetation Continuous Fields (VCF) product and values from literatures [16].

To preprocess 3BEM emission data to be used as inputs for WRF-Chem, the preprocessor PREP-CHEM-SRC version 1.5 [38] is employed. WMF-Chem employs the 3BEM daily emission data to simulate hourly emissions. To preprocess FINN emission data to be used as inputs for WRF-Chem, the preprocessor fire_emiss [45] is employed, where it applies the standard Western Regional Air Partnership (WRAP) diurnal profile to compute hourly emissions from daily values. The preprocessed hourly emission data for FINN are used as inputs for WRF-Chem. The plume rise of the wildfire smoke is computed by WRF-Chem using biomass burning emissions together with the environmental wind and temperature profile. The results of plume rise computation provide a vertical distribution of the emissions.

\subsection{Evaluation Method}

Since the smoke haze episode in the northern region of Thailand occurs during February-April and PM10 concentration peaks in March of each year, as Figure 3 shows, the biomass burning aerosol transport is simulated separately using biomass burning emissions from 3BEM and FINN for the 3-month period starting from 30 January-30 April for years 2014 and 2015. The first two days of the simulation period are treated as a spin-up period, and simulations during the period are not used for evaluation. To compute PM10 concentrations at the location and altitude above ground of each ground station, simulations at 5-km resolution are bilinearly interpolated for each horizontal layer and are then linearly interpolated in vertical direction between two neighboring levels surrounding the altitude above ground of the station.

Hourly, daily, and monthly average PM10 concentrations simulated using biomass burning emission inventories 3BEM and FINN for the 3-month period of 1 February-30 April are evaluated using measurements from 12 and 13 ground stations for years 2014 and 2015, respectively. Only 12 ground stations are used for 2014, since measurements for the station T39 do not exist for the study period. The simulations using 3BEM and FINN will be later called WRF-3BEM and WRF-FINN, respectively. Since PM10 simulations of 3BEM and FINN may be improved by averaging their simulations, their averages are also evaluated and are called WRF-AVG. The performance metrics employed for evaluating PM10 simulations include root mean squared errors (RMSEs), mean errors (MEs), which is E[simulations-measurements], and correlation coefficients (CCs) of simulations and measurements.

\section{Results}

\subsection{Evaluation of Simulated Hourly Average PM10 Concentrations}

Figure 5 compares time series of hourly average PM10 concentrations $\left(\mu \mathrm{g} \mathrm{m}^{-3}\right)$ simulated using 3BEM (WRF-3BEM) and those simulated using FINN (WRF-FINN) with measurements for February-April of 2014 for 12 ground stations. Figure 6 compares time series of hourly average PM10 concentrations $\left(\mu \mathrm{g} \mathrm{m}^{-3}\right)$ simulated using WRF-3BEM and WRF-FINN with measurements for 
February-April of 2015 for 13 ground stations. The comparisons of WRF-3BEM and WRF-FINN with measurements show that WRF-3BEM agrees with measurements much better than WRF-FINN does for most stations and both years. WRF-FINN simulations obviously have some spikes, which are overestimates, for most stations for both years. The WRF-FINN's significant overestimates are clearly seen for the station T73 for both years.
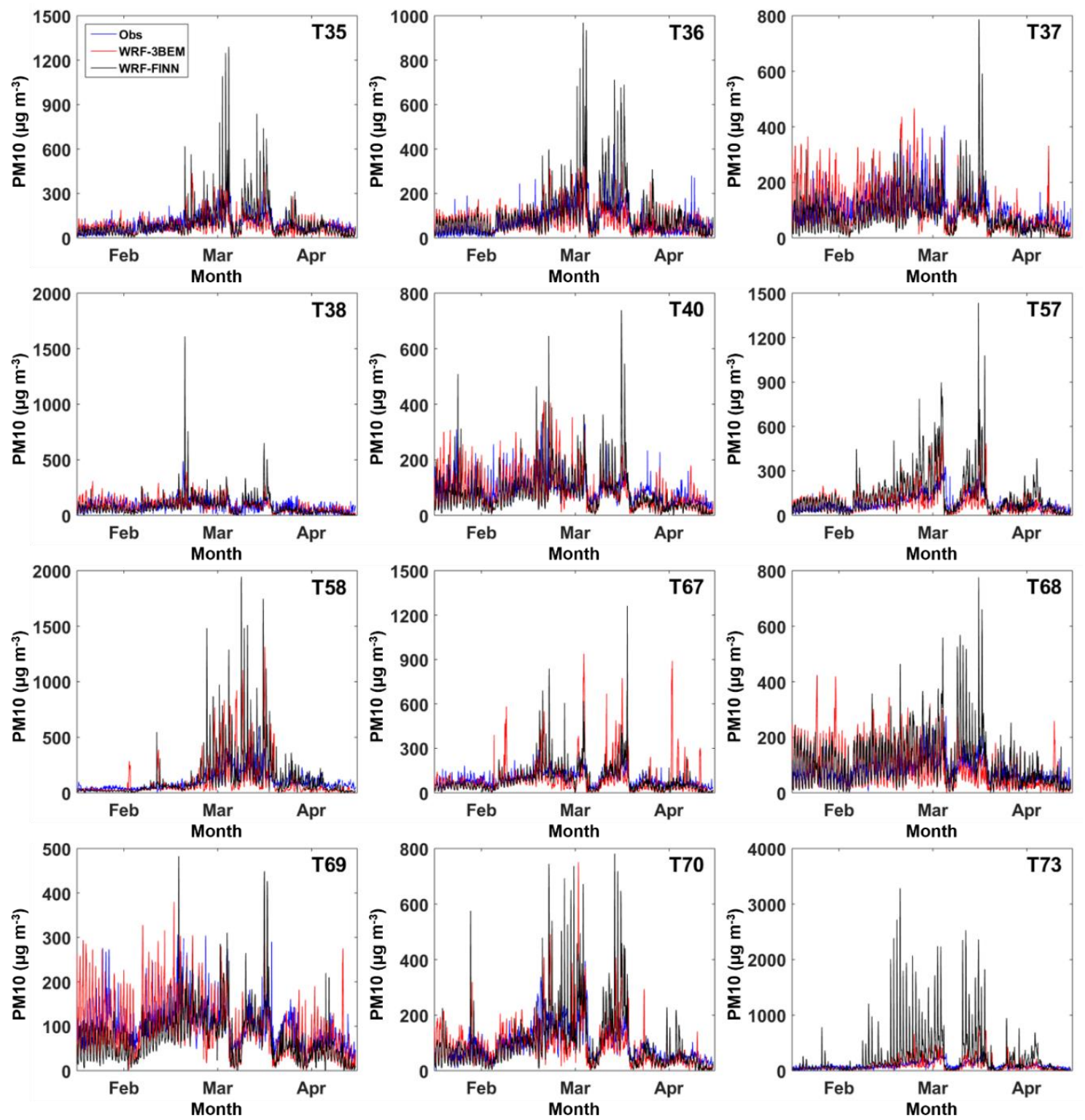

Figure 5. Comparisons of time series of measured hourly average PM10 concentrations $\left(\mu \mathrm{g} \mathrm{m}^{-3}\right)$ and simulations of WRF-3BEM and WRF-FINN for February-April in 2014 for 12 ground stations.

Table 3 shows the MEs (E[simulations-measurements]), RMSEs, and CCs of simulations and measurements for hourly average PM10 concentrations $\left(\mu \mathrm{g} \mathrm{m}^{-3}\right)$, simulated using WRF-3BEM and WRF-FINN and their averages (WRF-AVG) for February-April 2014 evaluated using measurements from 12 ground stations. Boldface highlights the model performing best for each performance metric. Accuracies of WRF-3BEM, WRF-FINN, and WRF-AVG vary for different stations. The three models also perform very differently. This emphasizes the importance of this study to evaluate PM10 simulations using different biomass burning emission inventories. WRF-3BEM performs best in terms of ME for most stations. MEs of WRF-3BEM are significantly lower than those of WRF-FINN and WRF-AVG. When RMSE is considered, WRF-3BEM performs best for five stations while WRF-AVG performs best 
for six stations. WRF-3BEM has best CCs for five stations while WRF-AVG has best CCs for seven stations. The overall results show that WRF-3BEM performs best among the three models, where its ME and RMSE are the lowest and its CC is close to that of WRF-AVG. WRF-FINN is least accurate.
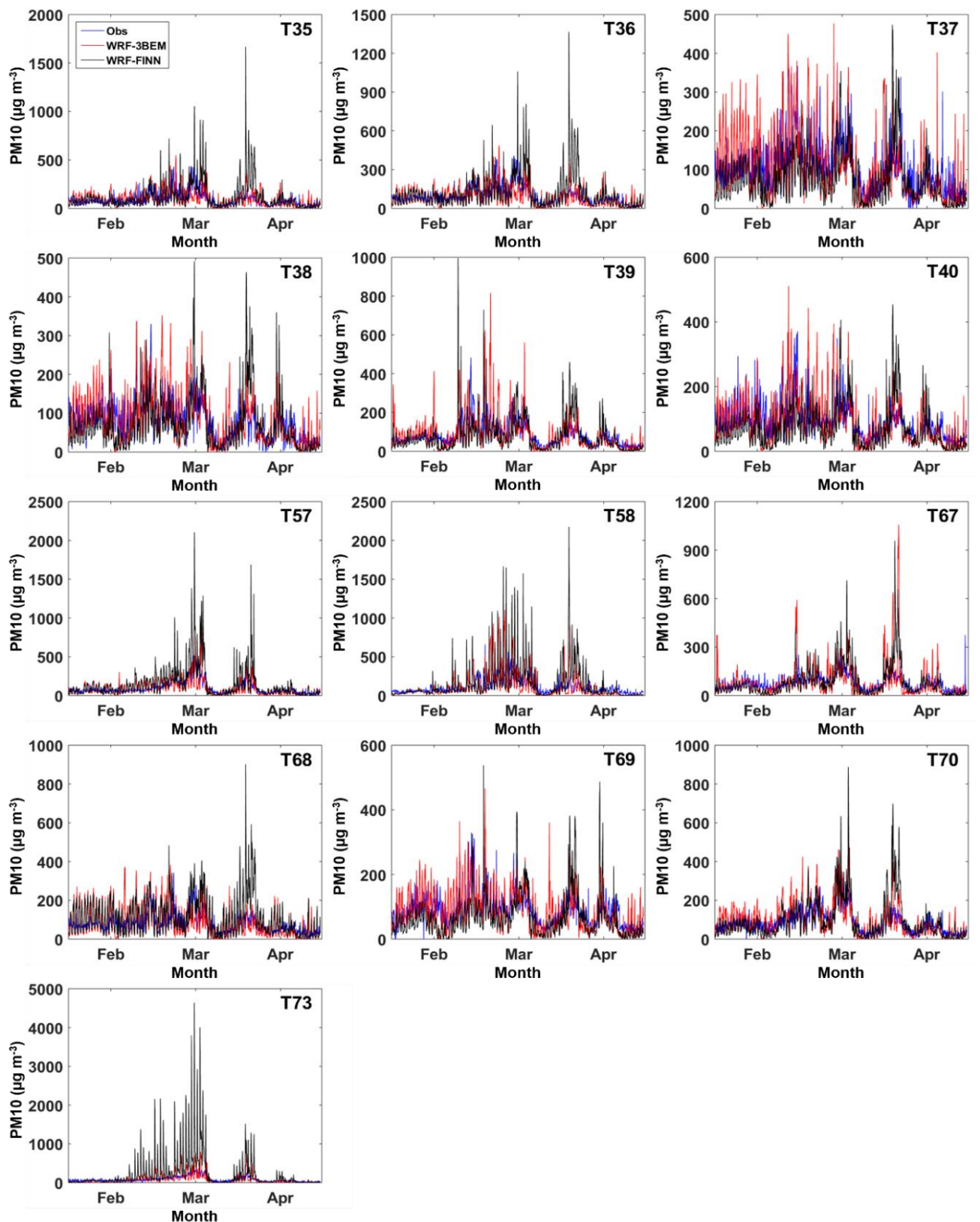

Figure 6. Comparisons of time series of measured hourly average PM10 concentrations $\left(\mu \mathrm{g} \mathrm{m}^{-3}\right)$ and simulations of WRF-3BEM and WRF-FINN for February-April in 2015 for 13 ground stations. 
Table 3. MEs (E[simulations-measurements]), RMSEs, and CCs of simulations and measurements for WRF-3BEM, WRF-FINN, and WRF-AVG simulated hourly average PM10 concentrations ( $\mu \mathrm{g} \mathrm{m}^{-3}$ ) for February-April of 2014 evaluated using measurements from 12 ground stations. (CC: correlation coefficient, RMSE: root mean squared error).

\begin{tabular}{cccccccccc}
\hline \multirow{2}{*}{ Station } & \multicolumn{3}{c}{ WRF-3BEM } & \multicolumn{3}{c}{ WRF-FINN } & \multicolumn{3}{c}{ WRF-AVG } \\
\cline { 2 - 11 } & ME & RMSE & CC & ME & RMSE & CC & ME & RMSE & CC \\
\hline T35 & -7.65 & $\mathbf{6 6 . 7 1}$ & 0.38 & 8.57 & 101.00 & 0.45 & $\mathbf{0 . 4 6}$ & 70.48 & $\mathbf{0 . 4 8}$ \\
T36 & $\mathbf{4 . 2 2}$ & $\mathbf{6 0 . 0 3}$ & 0.44 & 29.40 & 93.26 & 0.48 & 16.81 & 65.26 & $\mathbf{0 . 5 2}$ \\
T37 & $\mathbf{- 4 . 8 8}$ & 84.80 & 0.22 & -22.56 & 73.12 & $\mathbf{0 . 4 4}$ & -13.72 & $\mathbf{6 9 . 6 2}$ & 0.37 \\
T38 & $\mathbf{- 4 . 3 8}$ & $\mathbf{5 8 . 3 6}$ & $\mathbf{0 . 4 5}$ & -10.01 & 88.65 & 0.27 & -7.19 & 63.01 & 0.40 \\
T40 & $\mathbf{0 . 7 8}$ & 55.29 & $\mathbf{0 . 5 5}$ & -7.39 & 71.35 & 0.38 & -3.30 & $\mathbf{5 3 . 4 4}$ & 0.53 \\
T57 & $\mathbf{2 . 4 8}$ & $\mathbf{7 0 . 6 6}$ & 0.49 & 49.62 & 122.67 & $\mathbf{0 . 6 3}$ & 26.05 & 83.29 & $\mathbf{0 . 6 3}$ \\
T58 & $\mathbf{- 1 . 9 0}$ & 130.04 & $\mathbf{0 . 5 6}$ & 19.38 & 167.88 & 0.41 & 8.74 & $\mathbf{1 2 1 . 1 2}$ & $\mathbf{0 . 5 6}$ \\
T67 & $\mathbf{- 1 . 5 2}$ & 102.71 & 0.41 & -3.77 & $\mathbf{7 1 . 8 0}$ & $\mathbf{0 . 6 5}$ & -2.64 & 71.93 & 0.60 \\
T68 & $\mathbf{- 1 . 2 6}$ & 66.05 & 0.36 & 26.54 & 81.63 & $\mathbf{0 . 4 9}$ & 12.64 & $\mathbf{6 2 . 3 2}$ & $\mathbf{0 . 4 9}$ \\
T69 & $\mathbf{- 2 . 0 8}$ & 62.58 & 0.37 & -24.35 & 59.87 & 0.43 & -13.22 & $\mathbf{5 3 . 9 9}$ & $\mathbf{0 . 4 4}$ \\
T70 & $\mathbf{- 4 . 7 5}$ & 68.39 & 0.57 & 8.16 & 91.29 & 0.49 & $\mathbf{1 . 7 1}$ & $\mathbf{6 8 . 5 2}$ & $\mathbf{0 . 5 8}$ \\
T73 & $\mathbf{- 1 . 2 2}$ & $\mathbf{9 4 . 7 9}$ & $\mathbf{0 . 5 4}$ & 119.46 & 343.72 & 0.40 & 59.12 & 191.59 & 0.48 \\
All & $\mathbf{- 1 . 8 3}$ & $\mathbf{7 9 . 8 4}$ & 0.46 & 16.43 & 137.24 & 0.38 & 7.30 & 89.92 & $\mathbf{0 . 4 8}$ \\
\hline
\end{tabular}

Boldface highlights the model performing best for each performance metric.

Table 4 shows MEs (E[simulations-measurements]), RMSEs, and CCs of simulations and measurements for simulated hourly average PM10 concentrations $\left(\mu \mathrm{g} \mathrm{m}^{-3}\right)$ of WRF-3BEM, WRF-FINN, and WRF-AVG for February-April 2015, evaluated using measurements from 13 ground stations. Results are similar to those for 2014. WRF-3BEM performs best in terms of ME for all stations. In terms of RMSE, WRF-3BEM performs best for six stations while WRF-AVG performs best for seven stations. WRF-AVG performs best in terms of CC when stations are considered separately. Overall results show that WRF-3BEM performs best for all performance metrics, where its ME is close to zero.

Table 4. MEs (E[simulations-measurements]), RMSEs, and CCs of simulations and measurements for WRF-3BEM, WRF-FINN, and WRF-AVG simulated hourly average PM10 concentrations $\left(\mu \mathrm{g} \mathrm{m}^{-3}\right)$ for February-April of 2015 evaluated using measurements from 13 ground stations.

\begin{tabular}{cccccccccc}
\hline \multirow{2}{*}{ Station } & \multicolumn{3}{c}{ WRF-3BEM } & \multicolumn{3}{c}{ WRF-FINN } & \multicolumn{3}{c}{ WRF-AVG } \\
\cline { 2 - 10 } & ME & RMSE & CC & ME & RMSE & CC & ME & RMSE & CC \\
\hline T35 & $\mathbf{5 . 9 7}$ & $\mathbf{7 8 . 7 6}$ & 0.41 & 26.97 & 124.99 & 0.42 & 16.47 & 86.17 & $\mathbf{0 . 4 7}$ \\
T36 & $\mathbf{- 5 . 0 5}$ & $\mathbf{6 7 . 2 5}$ & 0.50 & 25.59 & 114.44 & 0.46 & 10.27 & 75.73 & $\mathbf{0 . 5 4}$ \\
T37 & $\mathbf{2 . 4 6}$ & 76.93 & 0.44 & -23.90 & 69.70 & 0.44 & -10.72 & $\mathbf{6 2 . 2 7}$ & $\mathbf{0 . 5 0}$ \\
T38 & $\mathbf{0 . 2 5}$ & 49.41 & $\mathbf{0 . 6 0}$ & -11.54 & 62.22 & 0.43 & -5.65 & $\mathbf{4 6 . 6 0}$ & 0.59 \\
T39 & $\mathbf{1 . 0 1}$ & 63.72 & $\mathbf{0 . 6 3}$ & -6.82 & 77.63 & 0.43 & -2.90 & $\mathbf{5 6 . 2 5}$ & 0.63 \\
T40 & $\mathbf{- 3 . 1 6}$ & 63.09 & 0.50 & -19.78 & 67.65 & 0.39 & -11.47 & $\mathbf{5 5 . 6 6}$ & $\mathbf{0 . 5 2}$ \\
T57 & $\mathbf{- 2 . 7 0}$ & $\mathbf{7 4 . 1 9}$ & 0.64 & 54.78 & 170.95 & 0.64 & 26.04 & 105.94 & $\mathbf{0 . 6 8}$ \\
T58 & $\mathbf{2 . 4 5}$ & $\mathbf{1 3 0 . 2 0}$ & $\mathbf{0 . 5 8}$ & 35.78 & 209.88 & 0.31 & 19.11 & 141.79 & 0.50 \\
T67 & $\mathbf{2 . 5 2}$ & 91.87 & 0.43 & 5.23 & 73.02 & $\mathbf{0 . 6 5}$ & 3.88 & $\mathbf{7 1 . 1 4}$ & 0.60 \\
T68 & $\mathbf{2 . 9 0}$ & 69.26 & 0.40 & 31.79 & 86.77 & 0.52 & 17.34 & $\mathbf{6 5 . 7 2}$ & $\mathbf{0 . 5 3}$ \\
T69 & $\mathbf{- 2 . 2 0}$ & 53.79 & 0.53 & -19.91 & 63.11 & 0.44 & -11.05 & $\mathbf{4 9 . 7 9}$ & $\mathbf{0 . 5 5}$ \\
T70 & $\mathbf{2 . 6 8}$ & $\mathbf{5 9 . 5 9}$ & 0.69 & 7.08 & 79.21 & 0.63 & 4.88 & 61.22 & $\mathbf{0 . 7 0}$ \\
T73 & $\mathbf{0 . 8 3}$ & $\mathbf{9 2 . 9 8}$ & $\mathbf{0 . 6 4}$ & 128.47 & 401.57 & 0.52 & 64.65 & 220.68 & 0.60 \\
All & $\mathbf{0 . 6 3}$ & $\mathbf{7 7 . 3 2}$ & $\mathbf{0 . 5 5}$ & 18.17 & 153.50 & 0.41 & 9.40 & 96.55 & 0.53 \\
\hline
\end{tabular}

Boldface highlights the model performing best for each performance metric.

Figure 7 shows scatter plots comparing measured hourly average PM10 concentrations and simulations of WRF-3BEM, WRF-FINN, and WRF-AVG for February-April 2014 and 2015 for all 
ground stations. Results are consistent with those shown in Tables 3 and 4, that is, WRF-3BEM and WRF-AVG perform comparably in terms of CC and WRF-FINN performs worst.

\section{4}
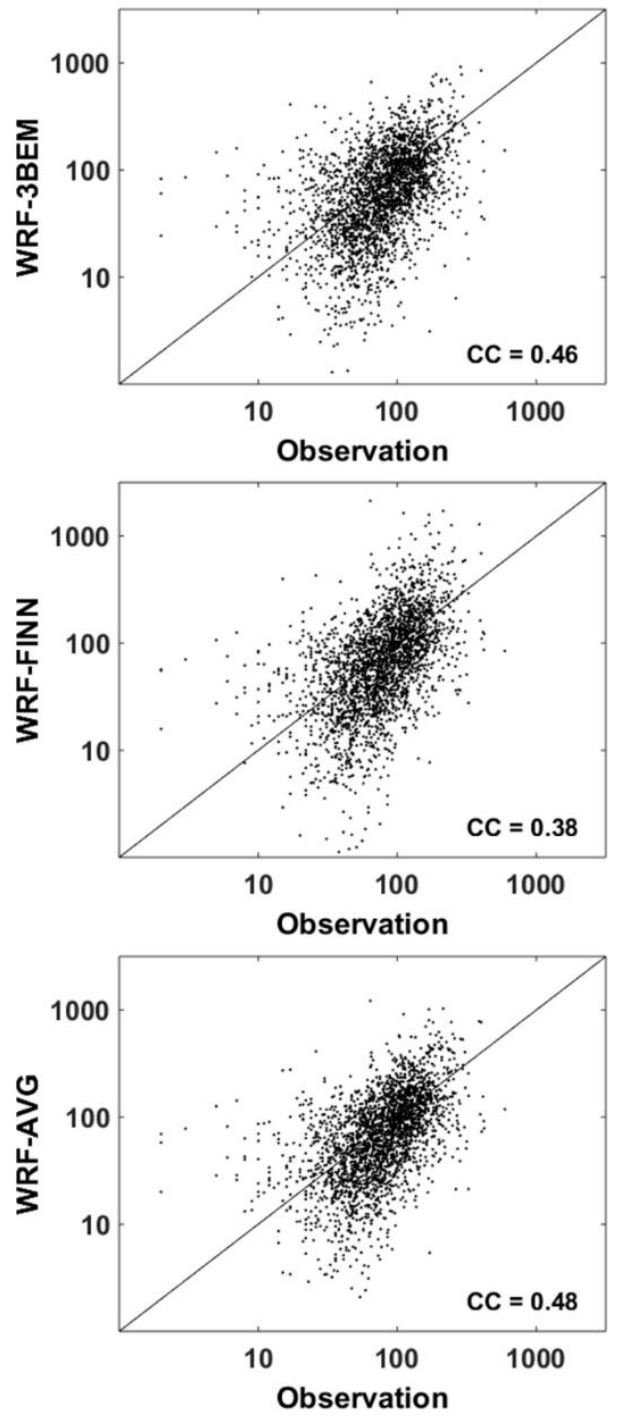

2015
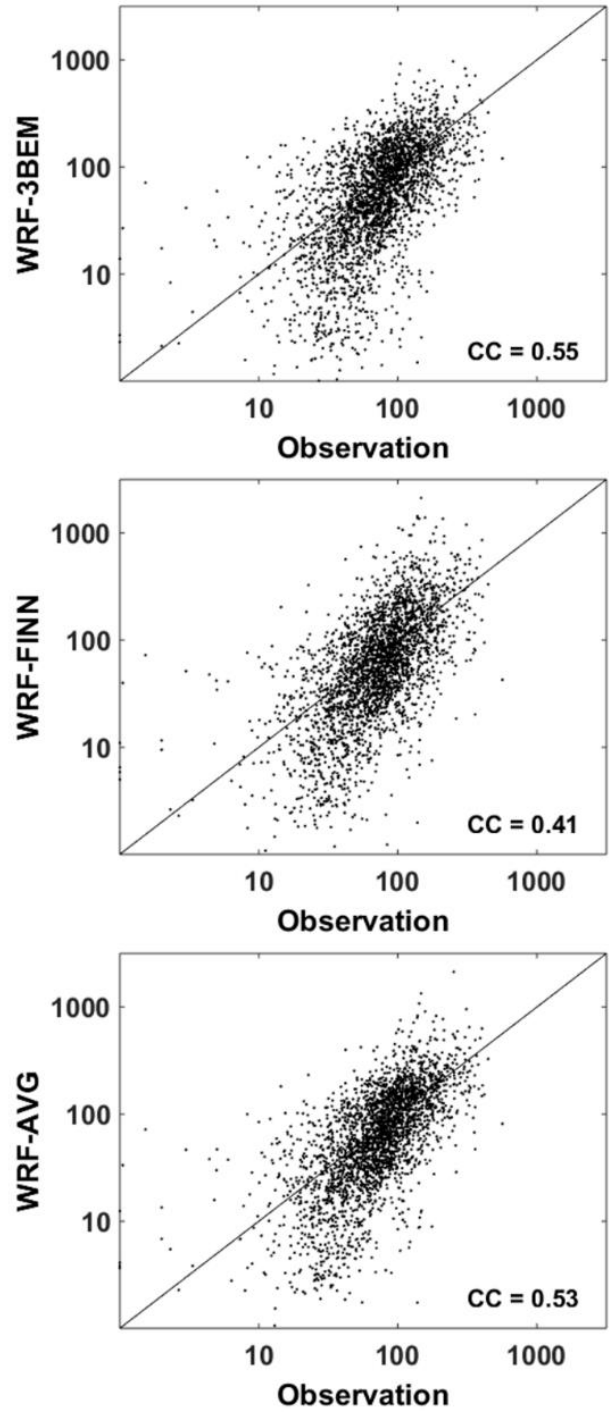

Figure 7. Scatter plots comparing measured hourly average PM10 concentrations $\left(\mu \mathrm{g} \mathrm{m}^{-3}\right)$ and simulations of WRF-3BEM, WRF-FINN, and WRF-AVG for February-April in 2014 and 2015 for all ground stations.

When results for all ground stations and for both years are combined, Table 5 shows overall MEs (E[simulations-measurements]), RMSEs, and CCs of simulations and measurements for WRF-3BEM, WRF-FINN, and WRF-AVG simulated hourly, daily, and monthly average PM10 concentrations $\left(\mu \mathrm{g} \mathrm{m}^{-3}\right)$. Boldface highlights the model performing best for each performance metric. WRF-3BEM simulated hourly PM10 concentrations are obviously most accurate in terms of ME, RMSE, and CC and are followed by those of WRF-AVG and WRF-FINN, respectively. ME of WRF-3BEM is almost zero, while those of WRF-FINN and WRF-AVG are much higher and are 17.34 and $8.40 \mu \mathrm{g} \mathrm{m}^{-3}$, respectively. RMSE of WRF-3BEM is 46.22 and is $15.99 \%$ less than those of WRF-FINN and WRF-AVG, respectively. CC of WRF-3BEM is close to that of WRF-AVG and is much better than that of WRF-FINN. 
Table 5. Overall MEs (E[simulations-measurements]), RMSEs, and CCs of simulations and measurements for WRF-3BEM, WRF-FINN, and WRF-AVG simulated hourly, daily, and monthly average PM10 concentrations $\left(\mu \mathrm{g} \mathrm{m}^{-3}\right)$ for February-April of 2014 and 2015 evaluated using measurements from all 12 ground stations.

\begin{tabular}{cccccccccc}
\hline \multirow{2}{*}{ PM10 } & \multicolumn{3}{c}{ WRF-3BEM } & \multicolumn{3}{c}{ WRF-FINN } & \multicolumn{3}{c}{ WRF-AVG } \\
\cline { 2 - 10 } & ME & RMSE & CC & ME & RMSE & CC & ME & RMSE & CC \\
\hline Hourly & $\mathbf{- 0 . 5 4}$ & $\mathbf{7 8 . 5 2}$ & $\mathbf{0 . 5 1}$ & 17.34 & 146.00 & 0.40 & 8.40 & 93.46 & 0.50 \\
Daily & $\mathbf{- 0 . 1 8}$ & $\mathbf{4 0 . 9 4}$ & 0.76 & 19.03 & 92.23 & 0.70 & 9.43 & 56.79 & $\mathbf{0 . 7 7}$ \\
Monthly & $\mathbf{- 2 . 0 2}$ & $\mathbf{1 4 . 8 1}$ & $\mathbf{0 . 8 9}$ & 14.13 & 52.87 & 0.63 & 6.06 & 27.95 & 0.79 \\
\hline
\end{tabular}

Boldface highlights the model performing best for each performance metric.

\subsection{Evaluation of Simulated Daily Average PM10 Concentrations}

Figure 8 compares time series of measured daily average PM10 concentrations $\left(\mu \mathrm{g} \mathrm{m}^{-3}\right)$ and simulations of WRF-3BEM and WRF-FINN for February-April in 2014 for 12 ground stations. Figure 9 compares time series of measured daily average PM10 concentrations $\left(\mu \mathrm{g} \mathrm{m}^{-3}\right)$ and simulations of WRF-3BEM and WRF-FINN for February-April 2015 for 13 ground stations. WRF-3BEM agrees well with measurements and performs obviously better than WRF-FINN does. The overestimates of WRF-FINN are clearly shown in several stations and both years. This is consistent with results for simulated hourly average PM10 concentrations.
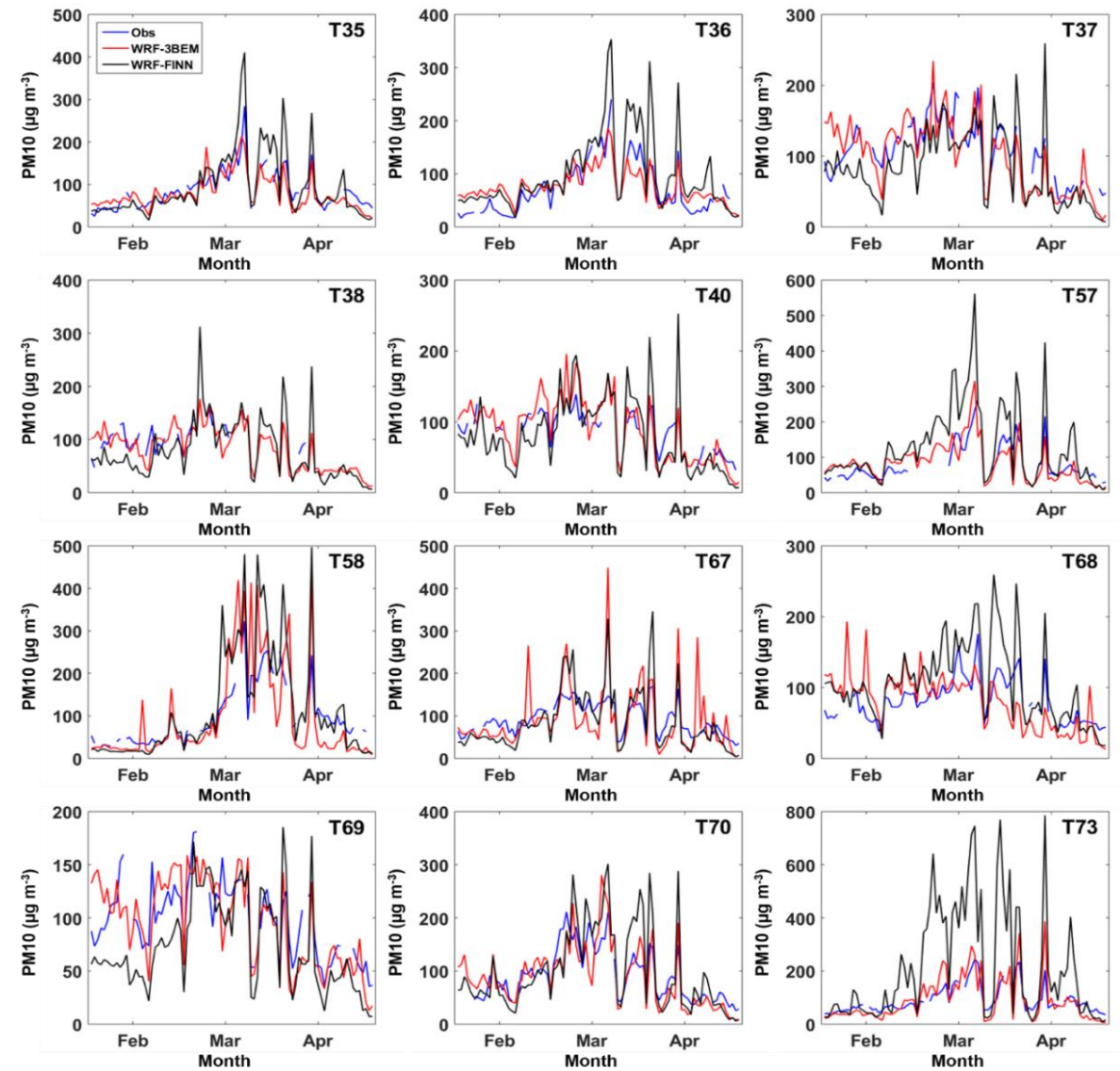

Figure 8. Comparisons of time series of measured daily average PM10 concentrations $\left(\mu \mathrm{g} \mathrm{m}^{-3}\right)$ and simulations of WRF-3BEM and WRF-FINN for February-April in 2014 for 12 ground stations. 

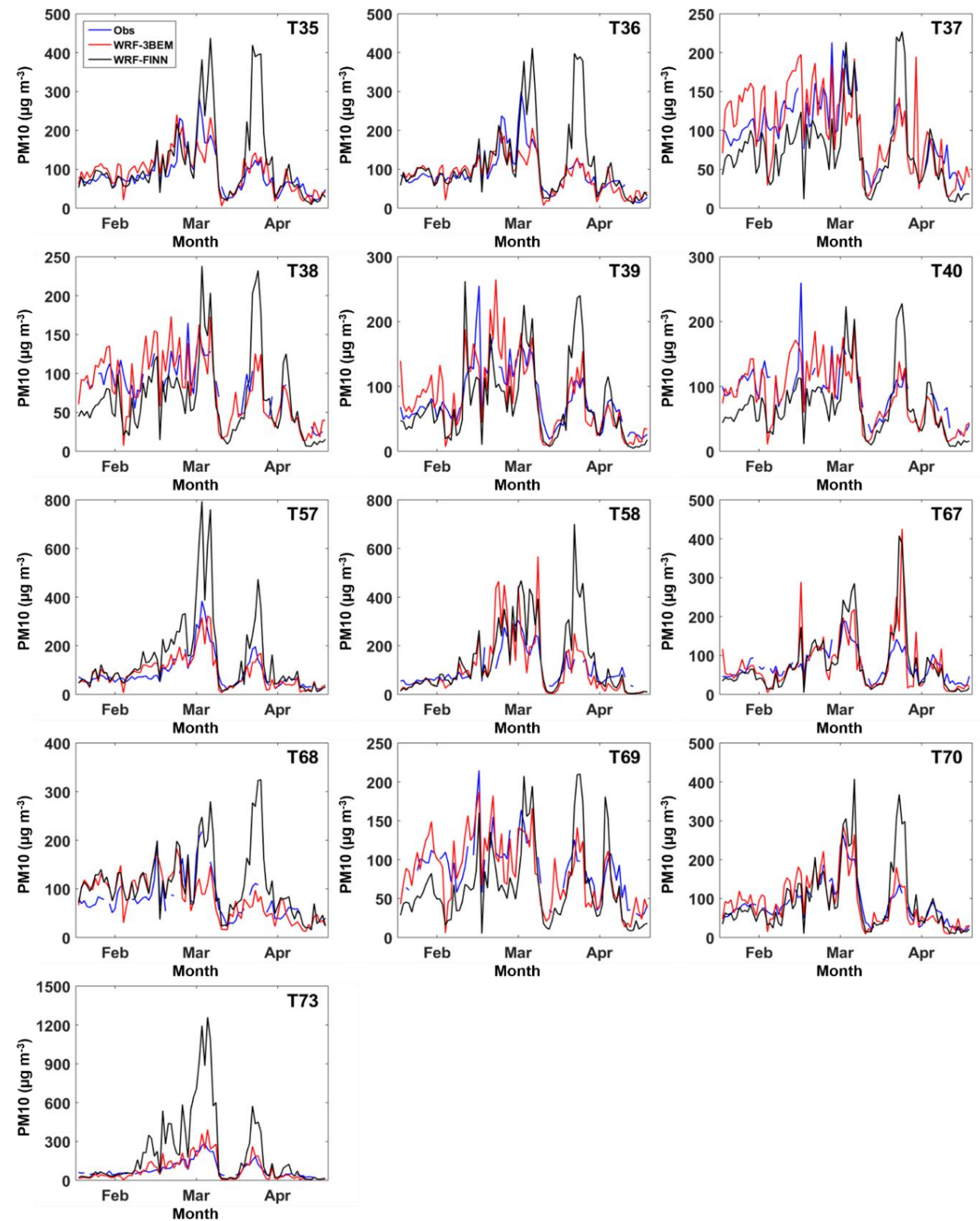

Figure 9. Comparisons of time series of measured daily average PM10 concentrations $\left(\mu \mathrm{g} \mathrm{m}^{-3}\right)$ and simulations of WRF-3BEM and WRF-FINN for February-April in 2015 for 13 ground stations.

Table 6 shows MEs (E[simulations-measurements]), RMSEs, and CCs of simulations and measurements for simulated daily average PM10 concentrations $\left(\mu \mathrm{g} \mathrm{m}^{-3}\right)$ of WRF-3BEM, WRF-FINN, and WRF-AVG for February-April 2014 evaluated using measurements from 12 ground stations. Daily averaging significantly improves the accuracies of all models when compared with the accuracies for hourly simulations. WRF-3BEM, WRF-FINN, and WRF-AVG perform very differently. WRF-3BEM performs best for eight stations in terms of ME and seven stations in terms of RMSE. WRF-AVG has best CCs for seven stations. Overall results are consistent with those shown in Table 3. WRF-3BEM performs best and is followed by WRF-AVG and WRF-FINN, respectively. WRF-3BEM has the lowest overall ME and RMSE and its CC is close to that of WRF-AVG. 
Table 6. MEs (E[simulations-measurements]), RMSEs, and CCs of simulations and measurements for WRF-3BEM, WRF-FINN, and WRF-AVG simulated daily average PM10 concentrations $\left(\mu \mathrm{g} \mathrm{m}^{-3}\right)$ for February-April of 2014 evaluated using measurements from 12 ground stations.

\begin{tabular}{cccccccccc}
\hline \multirow{2}{*}{ Station } & \multicolumn{3}{c}{ WRF-3BEM } & \multicolumn{3}{c}{ WRF-FINN } & \multicolumn{3}{c}{ WRF-AVG } \\
\cline { 2 - 11 } & ME & RMSE & CC & ME & RMSE & CC & ME & RMSE & CC \\
\hline T35 & -7.54 & $\mathbf{2 7 . 9 2}$ & 0.81 & 8.88 & 45.40 & 0.90 & 0.67 & 28.43 & 0.89 \\
T36 & $\mathbf{5 . 4 8}$ & $\mathbf{2 9 . 2 0}$ & 0.82 & 31.95 & 50.65 & 0.87 & 18.71 & 30.94 & $\mathbf{0 . 8 8}$ \\
T37 & $\mathbf{- 2 . 8 7}$ & 38.63 & 0.65 & -22.11 & 43.43 & 0.68 & -12.49 & $\mathbf{3 5 . 5 4}$ & $\mathbf{0 . 7 1}$ \\
T38 & $\mathbf{- 3 . 7 5}$ & $\mathbf{2 7 . 9 5}$ & 0.56 & -15.18 & 40.15 & 0.69 & -9.47 & 29.14 & $\mathbf{0 . 6 9}$ \\
T40 & 1.61 & $\mathbf{2 6 . 7 5}$ & $\mathbf{0 . 8 2}$ & -4.69 & 39.07 & 0.74 & $\mathbf{- 1 . 5 4}$ & 29.20 & $\mathbf{0 . 8 2}$ \\
T57 & $\mathbf{2 . 0 1}$ & $\mathbf{3 8 . 1 5}$ & 0.76 & 50.99 & 87.69 & $\mathbf{0 . 8 8}$ & 26.50 & 53.08 & 0.86 \\
T58 & $\mathbf{- 2 . 7 3}$ & 64.84 & 0.83 & -22.01 & 78.20 & 0.88 & 9.64 & $\mathbf{6 3 . 5 9}$ & $\mathbf{0 . 8 9}$ \\
T67 & -4.43 & 56.99 & 0.65 & $\mathbf{- 3 . 6 8}$ & $\mathbf{4 4 . 8 5}$ & $\mathbf{0 . 8 6}$ & -4.06 & 46.20 & 0.79 \\
T68 & $\mathbf{- 1 . 2 1}$ & 35.51 & 0.44 & 27.47 & 44.06 & $\mathbf{0 . 8 4}$ & 13.13 & $\mathbf{3 0 . 2 5}$ & 0.75 \\
T69 & $\mathbf{- 1 . 4 8}$ & 28.94 & 0.73 & -24.94 & 38.73 & 0.73 & -13.21 & $\mathbf{2 7 . 9 0}$ & $\mathbf{0 . 7 9}$ \\
T70 & $\mathbf{- 3 . 7 7}$ & $\mathbf{3 5 . 0 6}$ & 0.81 & 9.67 & 49.03 & 0.83 & $\mathbf{2 . 9 5}$ & 36.88 & $\mathbf{0 . 8 5}$ \\
T73 & $\mathbf{- 2 . 0 5}$ & $\mathbf{4 6 . 1 5}$ & $\mathbf{0 . 8 5}$ & 116.06 & 206.60 & 0.81 & 57.01 & 117.52 & 0.84 \\
All & $\mathbf{- 1 . 7 7}$ & $\mathbf{4 0 . 3 8}$ & 0.75 & 18.19 & 81.32 & 0.71 & 8.21 & 51.98 & $\mathbf{0 . 7 7}$ \\
\hline
\end{tabular}

Boldface highlights the model performing best for each performance metric.

Table 7 shows MEs (E[simulations-measurements]), RMSEs, and CCs of simulations and measurements for simulated daily average PM10 concentrations $\left(\mu \mathrm{g} \mathrm{m}^{-3}\right)$ of WRF-3BEM, WRF-FINN, and WRF-AVG for February-April 2015 evaluated using measurements from 13 ground stations. Results are consistent with those for the hourly average PM10 concentrations shown in Table 4. WRF-3BEM performs best in terms of ME for all stations and performs best in terms of RMSE for nine stations. When individual stations are considered, WRF-AVG performs best in terms of CC. Overall results show that WRF-3BEM performs best for all performance metrics.

Table 7. MEs (E[simulations-measurements]), RMSEs, and CCs of simulations and measurements for WRF-3BEM, WRF-FINN, and WRF-AVG simulated daily average PM10 concentrations $\left(\mu \mathrm{g} \mathrm{m}^{-3}\right)$ for February-April of 2015 evaluated using measurements from 13 ground stations.

\begin{tabular}{cccccccccc}
\hline \multirow{2}{*}{ Station } & \multicolumn{3}{c}{ WRF-3BEM } & \multicolumn{3}{c}{ WRF-FINN } & \multicolumn{3}{c}{ WRF-AVG } \\
\cline { 2 - 10 } & ME & RMSE & CC & ME & RMSE & CC & ME & RMSE & CC \\
\hline T35 & $\mathbf{6 . 7 1}$ & $\mathbf{3 3 . 6 6}$ & 0.79 & 27.43 & 78.33 & 0.72 & 17.07 & 46.07 & $\mathbf{0 . 8 0}$ \\
T36 & $\mathbf{- 5 . 0 2}$ & $\mathbf{3 4 . 3 1}$ & $\mathbf{0 . 7 8}$ & 26.68 & 75.85 & 0.68 & 10.83 & 43.13 & 0.77 \\
T37 & $\mathbf{4 . 5 3}$ & 35.15 & 0.74 & -25.21 & 42.08 & 0.75 & -10.34 & $\mathbf{2 7 . 9 1}$ & $\mathbf{0 . 8 3}$ \\
T38 & $\mathbf{0 . 2 4}$ & $\mathbf{2 5 . 3 8}$ & $\mathbf{0 . 7 8}$ & -13.70 & 43.42 & 0.59 & -6.73 & 28.07 & 0.75 \\
T39 & $\mathbf{0 . 6 8}$ & $\mathbf{3 1 . 8 6}$ & $\mathbf{0 . 8 0}$ & -5.95 & 44.92 & 0.69 & -2.64 & 32.96 & 0.79 \\
T40 & $\mathbf{- 2 . 9 5}$ & $\mathbf{3 3 . 1 9}$ & 0.71 & -21.69 & 46.62 & 0.58 & -12.32 & 33.21 & $\mathbf{0 . 7 2}$ \\
T57 & $\mathbf{- 2 . 3 2}$ & $\mathbf{3 6 . 7 3}$ & 0.87 & 55.38 & 116.49 & 0.89 & 26.53 & 64.59 & $\mathbf{0 . 9 0}$ \\
T58 & $\mathbf{2 . 3 5}$ & 82.30 & 0.78 & 36.41 & 106.69 & 0.80 & 19.38 & $\mathbf{8 1 . 2 3}$ & $\mathbf{0 . 8 4}$ \\
T67 & $\mathbf{3 . 9 8}$ & 54.09 & 0.68 & 6.64 & 58.02 & $\mathbf{0 . 7 8}$ & 5.31 & $\mathbf{5 1 . 6 3}$ & 0.76 \\
T68 & $\mathbf{3 . 8 7}$ & 37.89 & 0.60 & 28.34 & 51.18 & 0.74 & 16.11 & $\mathbf{3 4 . 2 0}$ & $\mathbf{0 . 7 7}$ \\
T69 & $\mathbf{- 3 . 5 4}$ & $\mathbf{2 7 . 2 4}$ & $\mathbf{0 . 7 9}$ & -21.70 & 43.85 & 0.65 & -12.62 & 29.49 & 0.78 \\
T70 & $\mathbf{2 . 9 7}$ & $\mathbf{3 1 . 1 7}$ & $\mathbf{0 . 8 7}$ & 5.62 & 52.70 & 0.80 & 4.29 & 36.03 & $\mathbf{0 . 8 7}$ \\
T73 & $\mathbf{3 . 6 0}$ & $\mathbf{4 3 . 7 4}$ & 0.90 & 148.01 & 276.50 & $\mathbf{0 . 9 2}$ & 75.81 & 152.92 & $\mathbf{0 . 9 2}$ \\
A11 & $\mathbf{1 . 2 2}$ & $\mathbf{4 1 . 4 2}$ & $\mathbf{0 . 7 8}$ & 19.76 & 100.80 & 0.69 & 10.49 & 60.69 & 0.77 \\
\hline
\end{tabular}

Boldface highlights the model performing best for each performance metric.

Figure 10 shows scatter plots comparing measured daily average PM10 concentrations and simulations of WRF-3BEM, WRF-FINN, and WRF-AVG for February-April in 2014 and 2015 for 
all ground stations. Simulated daily average PM10 concentrations agree much better with the measurements than simulated hourly average PM10 concentrations do. CCs of WRF-3BEM are close to those of WRF-AVG and are better than those of WRF-FINN.
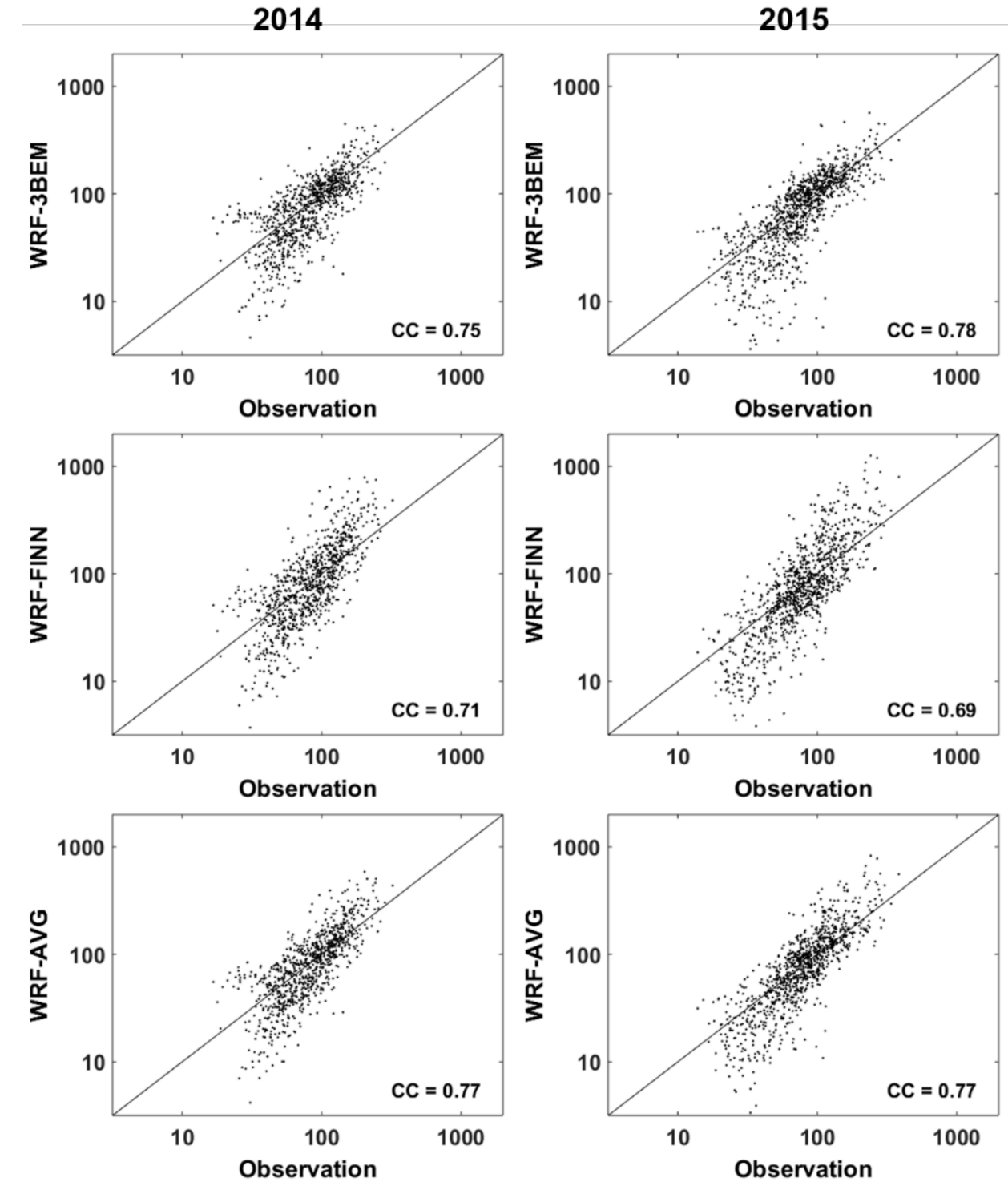

Figure 10. Scatter plots comparing measured daily average PM10 concentrations $\left(\mu \mathrm{g} \mathrm{m} \mathrm{m}^{-3}\right)$ and simulations of WRF-3BEM, WRF-FINN, and WRF-AVG for February-April 2014 and 2015 for all ground stations.

Overall MEs (E[simulations-measurements]), RMSEs, and CCs of simulations and measurements for WRF-3BEM, WRF-FINN, and WRF-AVG simulated daily average PM10 concentrations $\left(\mu \mathrm{g} \mathrm{m}^{-3}\right.$ ) are computed using all ground stations and both years and are shown in Table 5, where boldface highlights the model performing best for each performance metric. Results show that WRF-3BEM performs significantly better than WRF-FINN and WRF-AVG do. WRF-3BEM simulated daily average PM10 concentrations are almost unbiased, while MEs for WRF-FINN and WRF-AVG are 19.03 and $9.43\left(\mathrm{~g} \mathrm{~m} \mathrm{~m}^{-3}\right)$, respectively. WRF-FINN and WRF-AVG significantly overestimate daily average PM10 concentrations. WRF-3BEM also performs best in terms of RMSE. RMSE of WRF-3BEM is 55.61 and $27.91 \%$ lower than those of WRF-FINN and WRF-AVG, respectively. CC of WRF-3BEM is comparable to that of WRF-AVG and is better than that of WRF-FINN. 


\subsection{Evaluation of Simulated Monthly Average PM10 Concentrations}

Figures 11 and 12 compare simulated monthly average PM10 concentrations $\left(\mu \mathrm{g} \mathrm{m}^{-3}\right)$ at $2 \mathrm{~m}$ above ground of WRF-3BEM and WRF-FINN, where top to bottom rows are February, March, and April of 2014 and 2015, respectively. Both figures show significant differences between WRF-3BEM and WRF-FINN. WRF-FINN simulated monthly average PM10 concentrations are significantly higher than those of WRF-3BEM particularly in March and April in the upper portion of the figures. This emphasizes the need for this study to find a system that can provide useful simulations of biomass burning aerosol transport at high resolution. Results in the figures are also consistent with significant overestimates of WRF-FINN shown earlier in Sections 3.1 and 3.2.

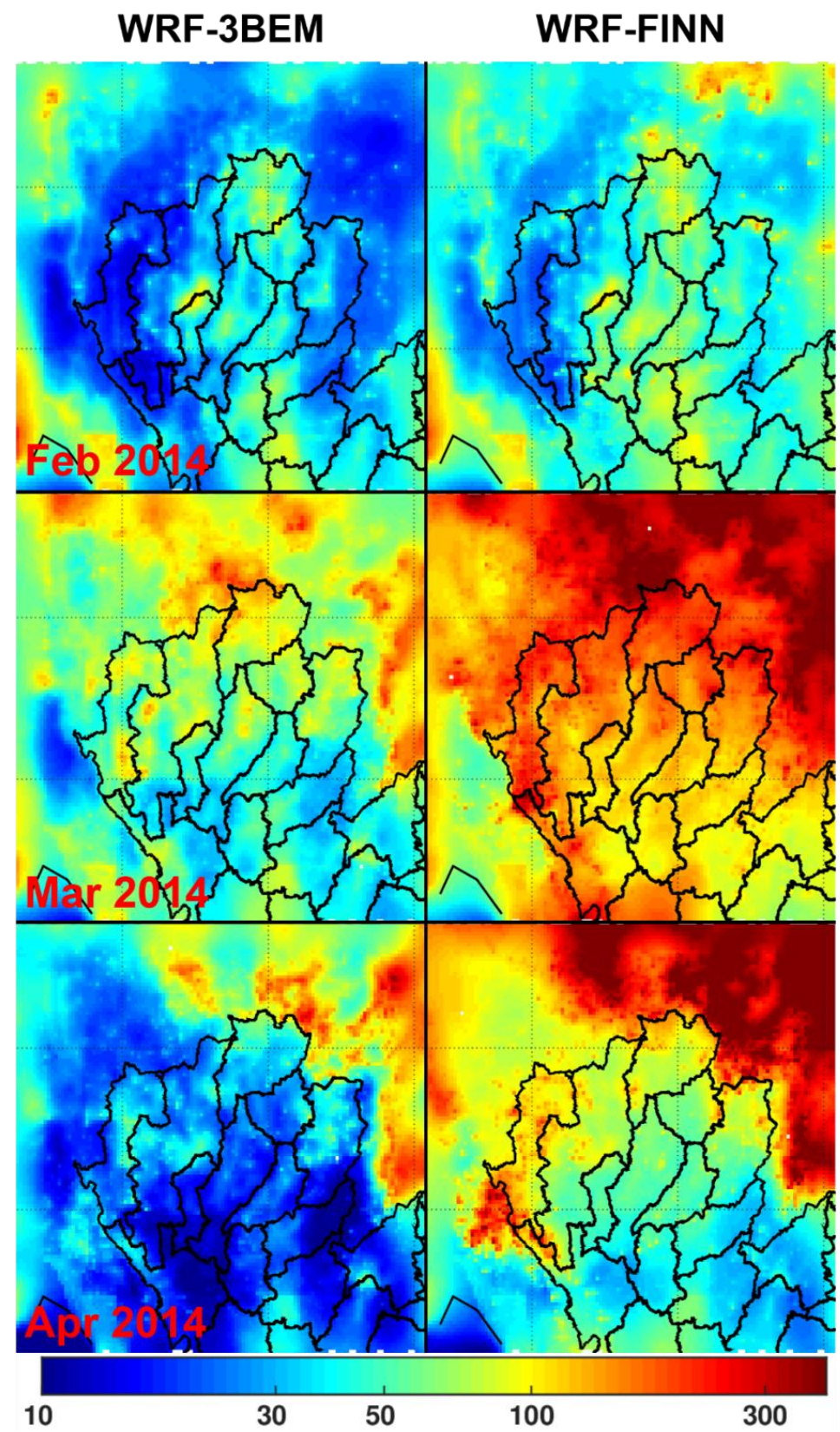

Figure 11. Comparisons of simulated monthly average PM10 concentrations $\left(\mu \mathrm{g} \mathrm{m}^{-3}\right)$ at $2 \mathrm{~m}$ above ground of WRF-3BEM and WRF-FINN. Top to bottom are February, March, and April of 2014. 
WRF-3BEM

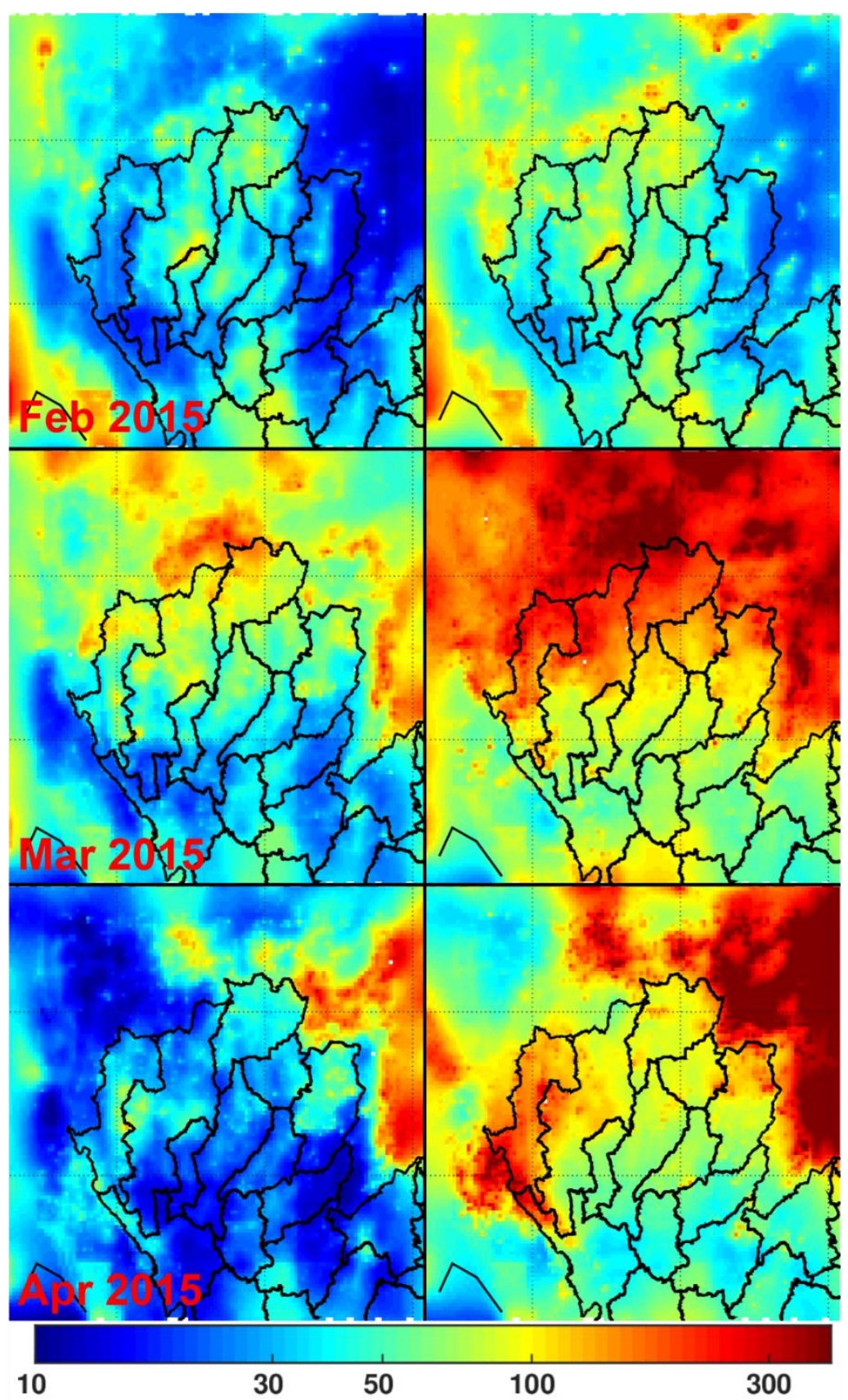

Figure 12. Comparisons of simulated monthly average PM10 concentrations $\left(\mu \mathrm{g} \mathrm{m}^{-3}\right)$ at $2 \mathrm{~m}$ above ground of WRF-3BEM and WRF-FINN. Top to bottom are February, March, and April of 2015.

Figure 13 compares measured monthly average PM10 concentrations $\left(\mu \mathrm{g} \mathrm{m}^{-3}\right)$ and simulations of WRF-3BEM and WRF-FINN for February-April of 2014 for 12 ground stations. Figure 14 compares the measured monthly average PM10 concentrations $\left(\mu \mathrm{g} \mathrm{m}^{-3}\right)$ and simulations of WRF-3BEM and WRF-FINN for February-April of 2015 for 13 ground stations. The significant overestimates of WRF-FINN in March and April of both years are clearly seen, particularly for the station T73, which is the most northern station. WRF-3BEM agrees well with measurements for most stations and months. 

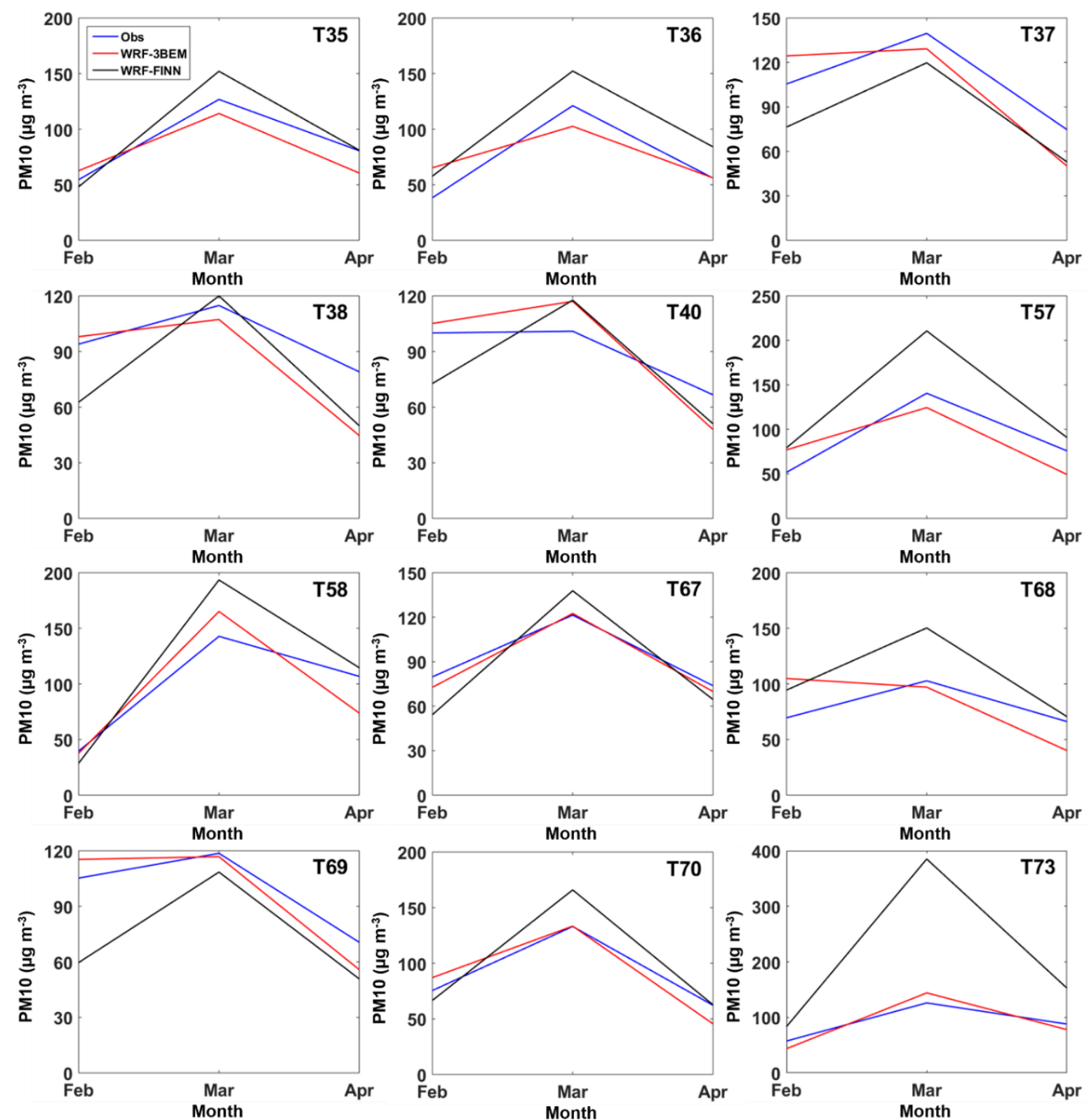

Figure 13. Comparisons of measured monthly average PM10 concentrations $\left(\mu \mathrm{g} \mathrm{m}^{-3}\right)$ and simulations of WRF-3BEM and WRF-FINN for February-April 2014 for 12 ground stations.

Table 8 shows MEs (E[simulations-measurements]), RMSEs, and CCs of simulations and measurements for simulated monthly average PM10 concentrations $\left(\mu \mathrm{g} \mathrm{m}^{-3}\right)$ of WRF-3BEM, WRF-FINN, and WRF-AVG for February-April 2014, evaluated using measurements from 12 ground stations. The RMSEs and CCs for the monthly average PM10 concentrations of all models are much better than those for their hourly and daily average PM10 concentrations, as expected. While WRF-3BEM has the lowest MEs for most stations, WRF-AVG performs best in terms of RMSE if individual stations are considered separately. The overall RMSE of WRF-3BEM is significantly lower than that of WRF-FINN and WRF-3AVG. WRF-FINN has the highest number of stations with best CC. The overall results in 2014 show that WRF-3BEM clearly performs best for all performance metrics. 

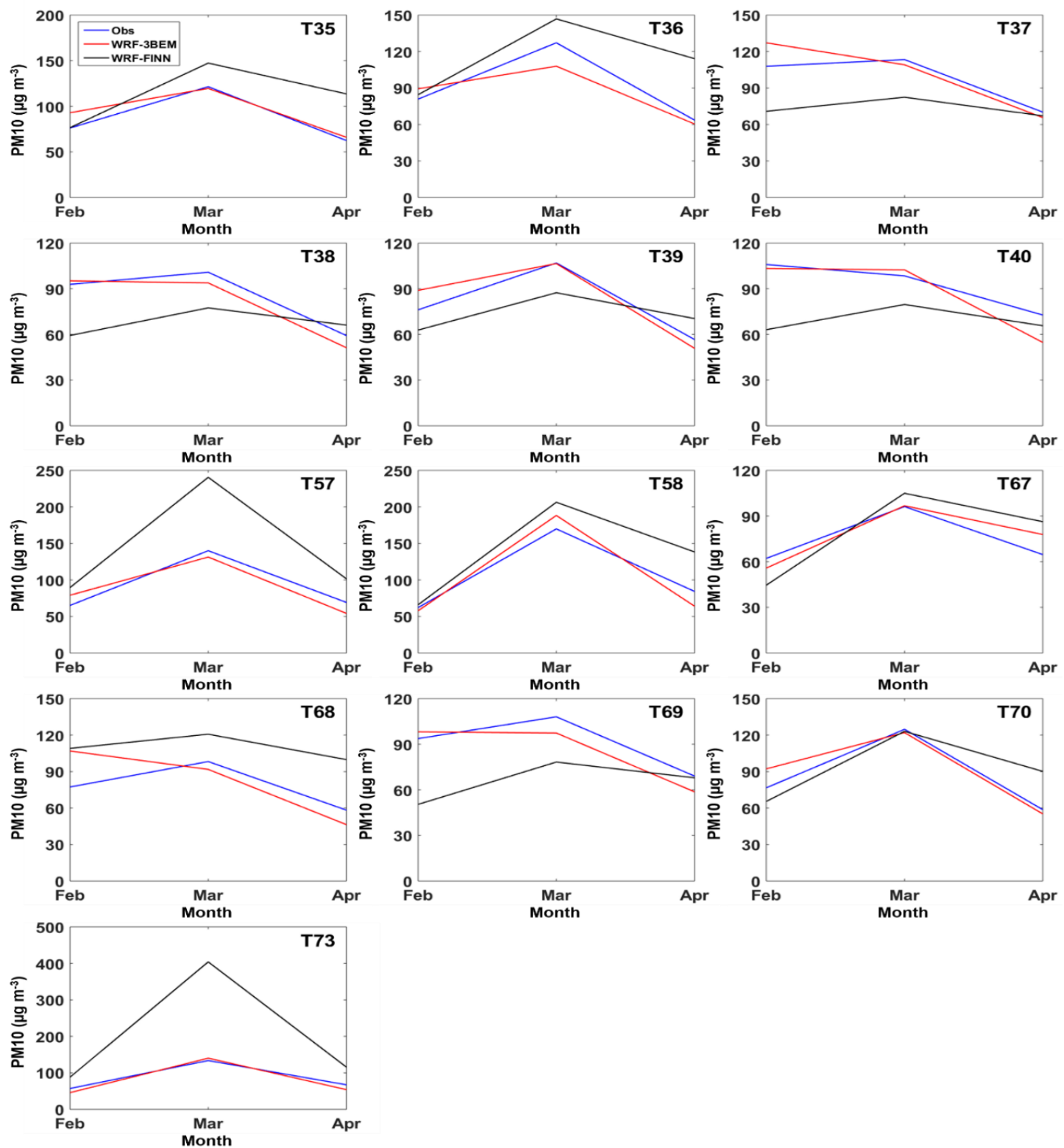

Figure 14. Comparisons of measured monthly average PM10 concentrations $\left(\mu \mathrm{g} \mathrm{m}^{-3}\right)$ and simulations of WRF-3BEM and WRF-FINN for February-April 2015 for 13 ground stations.

Table 9 shows MEs (E[simulations-measurements]), RMSEs, and CCs of simulations and measurements for simulated monthly average PM10 concentrations $\left(\mu \mathrm{g} \mathrm{m}^{-3}\right)$ of WRF-3BEM, WRF-FINN, and WRF-AVG for February-April 2015 evaluated using measurements from 13 ground stations. WRF-3BEM clearly performs best in terms of ME and RMSE. WRF-AVG performs best in terms of CC. ME and RMSE of WRF-3BEM for the station T73 are significantly less than those of WRF-FINN and WRF-AVG. WRF-3BEM clearly performs best in 2015 when all stations are considered. 
Table 8. MEs (E[simulations-measurements]), RMSEs, and CCs of simulations and measurements for WRF-3BEM, WRF-FINN, and WRF-AVG simulated monthly average PM10 concentrations $\left(\mu \mathrm{g} \mathrm{m}^{-3}\right)$ for February-April 2014 evaluated using measurements from 12 ground stations.

\begin{tabular}{cccccccccc}
\hline \multirow{2}{*}{ Station } & \multicolumn{3}{c}{ WRF-3BEM } & \multicolumn{3}{c}{ WRF-FINN } & \multicolumn{3}{c}{ WRF-AVG } \\
\cline { 2 - 11 } & ME & RMSE & CC & ME & RMSE & CC & ME & RMSE & CC \\
\hline T35 & -8.23 & 14.46 & 0.92 & 6.45 & 15.09 & $\mathbf{1 . 0 0}$ & $\mathbf{- 0 . 8 9}$ & $\mathbf{6 . 7 6}$ & 0.98 \\
T36 & $\mathbf{2 . 8 7}$ & 18.93 & 0.92 & 26.25 & 26.71 & $\mathbf{1 . 0 0}$ & 14.56 & $\mathbf{1 6 . 1 2}$ & $\mathbf{1 . 0 0}$ \\
T37 & $\mathbf{- 5 . 3 4}$ & 18.89 & 0.88 & -23.56 & 23.89 & $\mathbf{0 . 9 9}$ & -14.45 & $\mathbf{1 6 . 2 4}$ & 0.98 \\
T38 & $\mathbf{- 1 2 . 6 4}$ & 20.45 & 0.89 & -18.40 & 24.86 & 0.97 & -15.52 & $\mathbf{1 9 . 9 5}$ & $\mathbf{1 . 0 0}$ \\
T40 & 0.85 & $\mathbf{1 4 . 5 8}$ & $\mathbf{0 . 9 9}$ & -8.70 & 20.55 & 0.77 & -3.93 & 15.14 & 0.92 \\
T57 & $\mathbf{- 5 . 8 0}$ & 23.13 & 0.80 & 37.53 & 44.29 & $\mathbf{0 . 9 8}$ & 15.86 & $\mathbf{2 2 . 0 5}$ & 0.94 \\
T58 & $\mathbf{- 4 . 2 6}$ & 23.05 & 0.91 & 15.81 & 30.26 & $\mathbf{0 . 9 9}$ & 5.78 & $\mathbf{2 2 . 6 1}$ & 0.96 \\
T67 & $\mathbf{- 3 . 2 9}$ & $\mathbf{4 . 7 1}$ & $\mathbf{1 . 0 0}$ & -6.12 & 18.33 & 0.97 & -4.71 & 11.35 & 0.99 \\
T68 & $\mathbf{1 . 1 8}$ & 25.55 & 0.48 & 25.61 & 31.07 & $\mathbf{0 . 9 8}$ & 13.39 & $\mathbf{2 2 . 0 6}$ & 0.82 \\
T69 & $\mathbf{- 2 . 1 7}$ & $\mathbf{1 0 . 3 9}$ & 0.97 & -25.17 & 29.29 & 0.81 & -13.67 & 14.72 & $\mathbf{0 . 9 9}$ \\
T70 & $\mathbf{- 1 . 5 8}$ & 11.73 & 0.95 & 8.13 & 19.67 & 0.99 & 3.28 & $\mathbf{1 0 . 7 0}$ & $\mathbf{1 . 0 0}$ \\
T73 & $\mathbf{- 1 . 9 1}$ & $\mathbf{1 4 . 3 2}$ & $\mathbf{0 . 9 9}$ & 116.57 & 154.88 & 0.97 & 57.33 & 81.60 & 0.98 \\
All & $\mathbf{- 3 . 3 6}$ & $\mathbf{1 7 . 6 7}$ & $\mathbf{0 . 8 6}$ & 12.87 & 51.61 & 0.67 & 4.75 & 28.58 & 0.80 \\
\hline
\end{tabular}

Boldface highlights the model performing best for each performance metric.

Table 9. MEs (E[simulations-measurements]), RMSEs, and CCs of simulations and measurements for WRF-3BEM, WRF-FINN, and WRF-AVG simulated monthly average PM10 concentrations $\left(\mu \mathrm{g} \mathrm{m}^{-3}\right)$ for February-April 2015 evaluated using measurements from 13 ground stations.

\begin{tabular}{cccccccccc}
\hline \multirow{2}{*}{ Station } & \multicolumn{3}{c}{ WRF-3BEM } & \multicolumn{3}{c}{ WRF-FINN } & \multicolumn{3}{c}{ WRF-AVG } \\
\cline { 2 - 11 } & ME & RMSE & CC & ME & RMSE & CC & ME & RMSE & CC \\
\hline T35 & $\mathbf{6 . 1 3}$ & $\mathbf{9 . 9 7}$ & $\mathbf{0 . 9 5}$ & 25.80 & 33.08 & 0.72 & 15.97 & 17.93 & $\mathbf{0 . 9 5}$ \\
T36 & $\mathbf{- 4 . 6 4}$ & $\mathbf{1 2 . 2 7}$ & 0.93 & 24.59 & 31.37 & 0.72 & 9.97 & 14.11 & $\mathbf{0 . 9 6}$ \\
T37 & $\mathbf{3 . 5 0}$ & 11.69 & 0.92 & -23.66 & 27.90 & 0.77 & -10.08 & $\mathbf{1 1 . 5 9}$ & $\mathbf{0 . 9 8}$ \\
T38 & $\mathbf{- 4 . 2 3}$ & $\mathbf{6 . 2 9}$ & 0.98 & -16.70 & 23.97 & 0.32 & -10.47 & 12.60 & $\mathbf{0 . 9 9}$ \\
T39 & 2.20 & 8.12 & 0.94 & -6.36 & 15.80 & 0.76 & -2.08 & $\mathbf{6 . 2 0}$ & $\mathbf{1 . 0 0}$ \\
T40 & $\mathbf{- 5 . 5 5}$ & $\mathbf{1 0 . 7 6}$ & $\mathbf{0 . 9 8}$ & -22.89 & 27.31 & 0.16 & -14.22 & 15.58 & 0.90 \\
T57 & $\mathbf{- 3 . 2 4}$ & $\mathbf{1 2 . 8 5}$ & 0.93 & 52.41 & 62.55 & $\mathbf{1 . 0 0}$ & 24.58 & 29.16 & $\mathbf{1 . 0 0}$ \\
T58 & $\mathbf{- 2 . 0 6}$ & $\mathbf{1 5 . 9 7}$ & 0.99 & 31.46 & 37.69 & 0.94 & 14.70 & 18.60 & $\mathbf{1 . 0 0}$ \\
T67 & $\mathbf{2 . 4 6}$ & $\mathbf{8 . 4 7}$ & $\mathbf{0 . 8 8}$ & 4.25 & 16.88 & 0.78 & 3.35 & 12.50 & 0.82 \\
T68 & $\mathbf{3 . 7 4}$ & $\mathbf{1 8 . 8 0}$ & 0.70 & 31.93 & 32.86 & $\mathbf{1 . 0 0}$ & 17.83 & 20.20 & 0.83 \\
T69 & $\mathbf{- 5 . 5 3}$ & $\mathbf{8 . 9 6}$ & 0.93 & -24.73 & 30.34 & 0.22 & -15.13 & 16.52 & $\mathbf{0 . 9 8}$ \\
T70 & $\mathbf{3 . 1 2}$ & 9.35 & 0.95 & 6.20 & 19.33 & 0.76 & 4.66 & $\mathbf{8 . 2 9}$ & $\mathbf{0 . 9 9}$ \\
T73 & $\mathbf{- 6 . 0 2}$ & $\mathbf{1 0 . 7 7}$ & $\mathbf{1 . 0 0}$ & 116.65 & 159.67 & $\mathbf{1 . 0 0}$ & 55.31 & 80.82 & $\mathbf{1 . 0 0}$ \\
All & $\mathbf{- 0 . 7 8}$ & $\mathbf{1 1 . 5 6}$ & $\mathbf{0 . 9 3}$ & 15.30 & 54.00 & 0.58 & 7.26 & 27.36 & 0.78 \\
\hline
\end{tabular}

Boldface highlights the model performing best for each performance metric.

Figure 15 shows scatter plots comparing measured monthly average PM10 concentrations and simulations of WRF-3BEM, WRF-FINN, and WRF-AVG for February-April 2014 and 2015. WRF-3BEM performs much better than the other two models, where all points in the scatter plots stay close to the one-to-one lines, particularly for 2015. CCs of WRF-3BEM and measurements are as high as 0.86 and 0.93 for 2014 and 2015, respectively. WRF-3BEM simulations are almost unbiased for both years, which is consistent with those shown in Tables 8 and 9. WRF-FINN clearly performs worst. 
2014
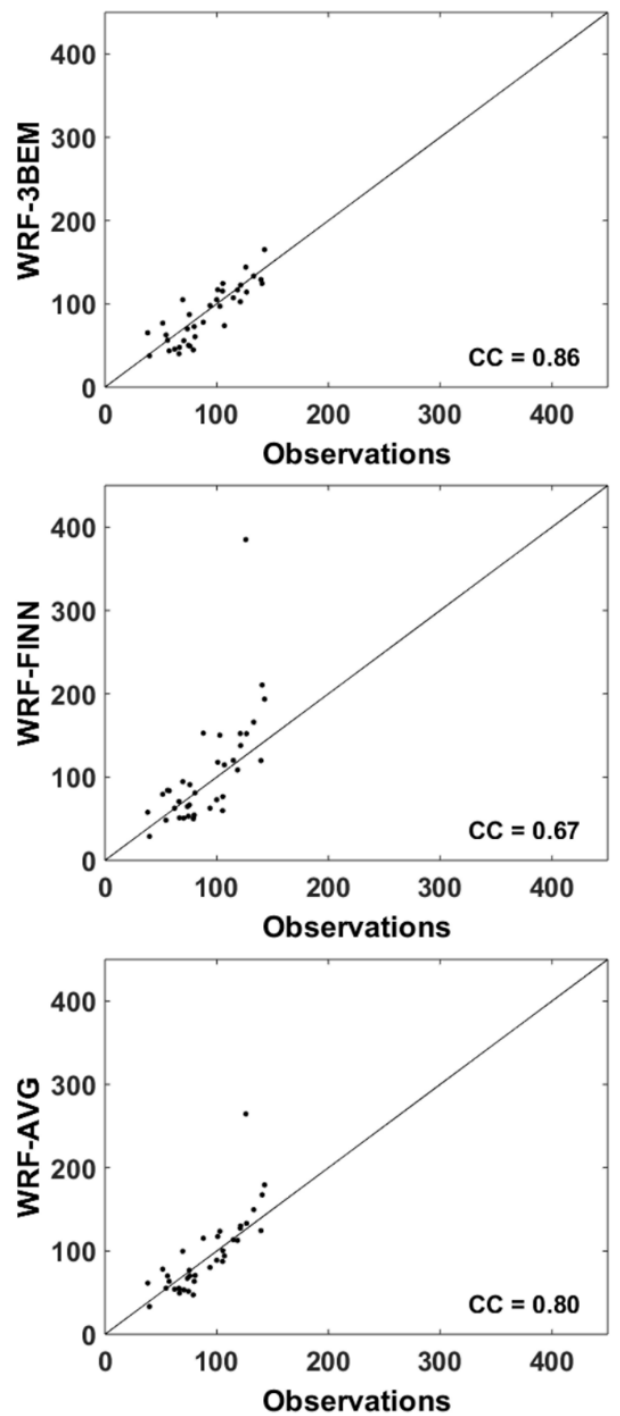

2015
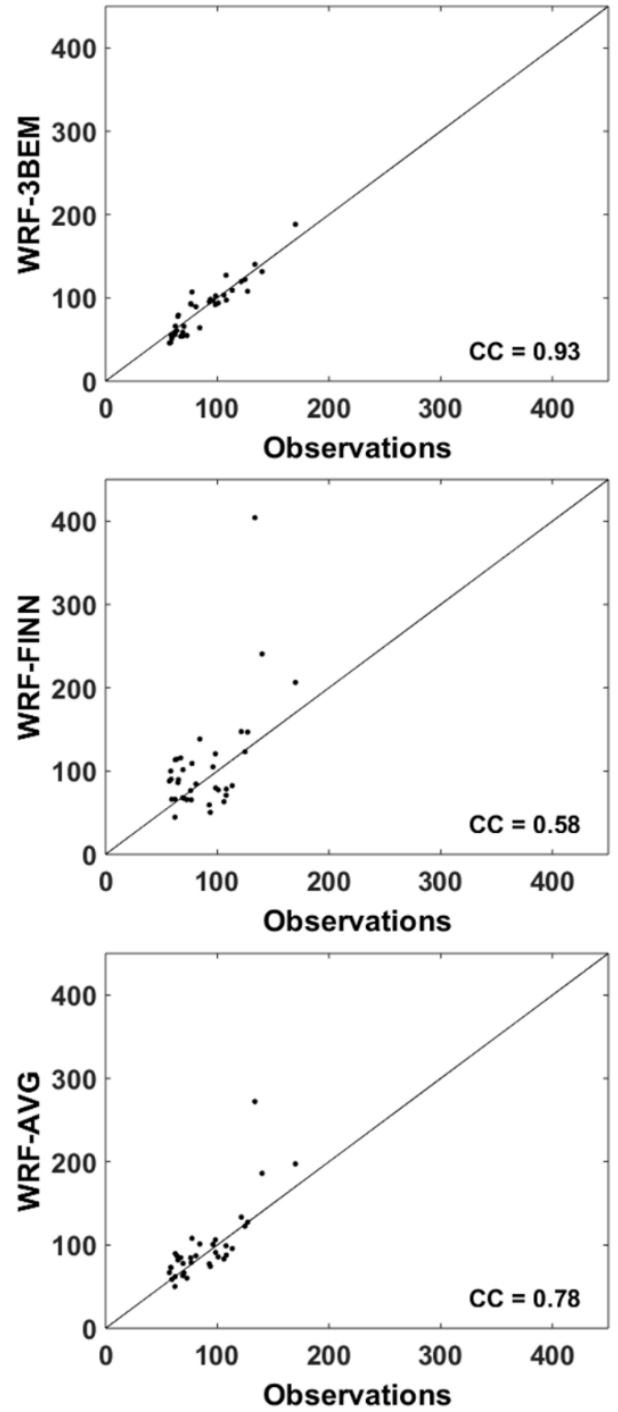

Figure 15. Scatter plots comparing measured monthly average PM10 concentrations $\left(\mu \mathrm{g} \mathrm{m}^{-3}\right)$ and simulations of WRF-3BEM, WRF-FINN, and WRF-AVG for February-April 2014 and 2015.

Table 5 shows overall MEs (E[simulations-measurements]), RMSEs, and CCs of simulations and measurements for WRF-3BEM, WRF-FINN, and WRF-AVG simulated monthly average PM10 concentrations $\left(\mathrm{\mu g} \mathrm{m}^{-3}\right)$ computed using all ground stations and for both years., where boldface highlights the model performing best for each performance metric. WRF-3BEM clearly performs best for all performance metrics and is followed by WRF-AVG and WRF-FINN, respectively. WRF-3BEM simulated monthly average PM10 concentrations are slightly underestimated, while those of WRF-FINN and WRF-AVG are significantly overestimated. The monthly average PM10 concentrations, computed using all ground stations and for both years for measurements WRF-3BEM, WRF-FINN, and WRF-AVG are $89.22,87.20,103.35$, and $95.27 \mathrm{\mu g} \mathrm{m}^{-3}$, respectively. The RMSE of WRF-3BEM is 72.00 and $47.01 \%$ less than those of WRF-FINN and WRF-AVG. CC of WRF-3BEM is 0.89 , which is obviously higher than those of the other two models, i.e., 0.63 for WRF-FINN and 0.79 for WRF-AVG.

\subsection{Comparisons of 3BEM and FINN Biomass Burning Emissions}

Results in Sections 3.1-3.3 clearly show that while WRF-3BEM simulated hourly, daily, and monthly PM10 concentrations agree well with measurements, those of WRF-FINN are significantly overestimated and have high spikes. Figures 13 and 14 show that the WRF-FINN overestimates are 
worst for the station T73, the most northern ground station in this study, in March of both 2014 and 2015. To investigate the reason for WRF-FINN's significant PM10 overestimates, the original 3BEM and FINN biomass burning emissions used as inputs for WRF-Chem are compared. Figure 16 compares the daily total 3BEM and FINN emissions $\left(\mathrm{kg} \mathrm{m}^{-2}\right.$ day $\left.{ }^{-1}\right)$ of carbon monoxide $(\mathrm{CO})$, sulfur dioxide $\left(\mathrm{SO}_{2}\right)$, and nitrogen oxide (NO) over the study area averaged over 31 days of March 2014. Black squares in each sub-figure show locations of ground stations employed in this study. Figure 17 compares daily total 3BEM and FINN emissions $\left(\mathrm{kg} \mathrm{m}^{-2} \mathrm{day}^{-1}\right)$ of $\mathrm{CO}, \mathrm{SO}_{2}$, and $\mathrm{NO}$ over the study area averaged over 31 days in March 2015. The 3BEM and FINN emission datasets also provide several other biomass burning species, but $\mathrm{CO}, \mathrm{SO}_{2}$, and $\mathrm{NO}$ are selected to illustrate the cause of WRF-FINN's overestimates.

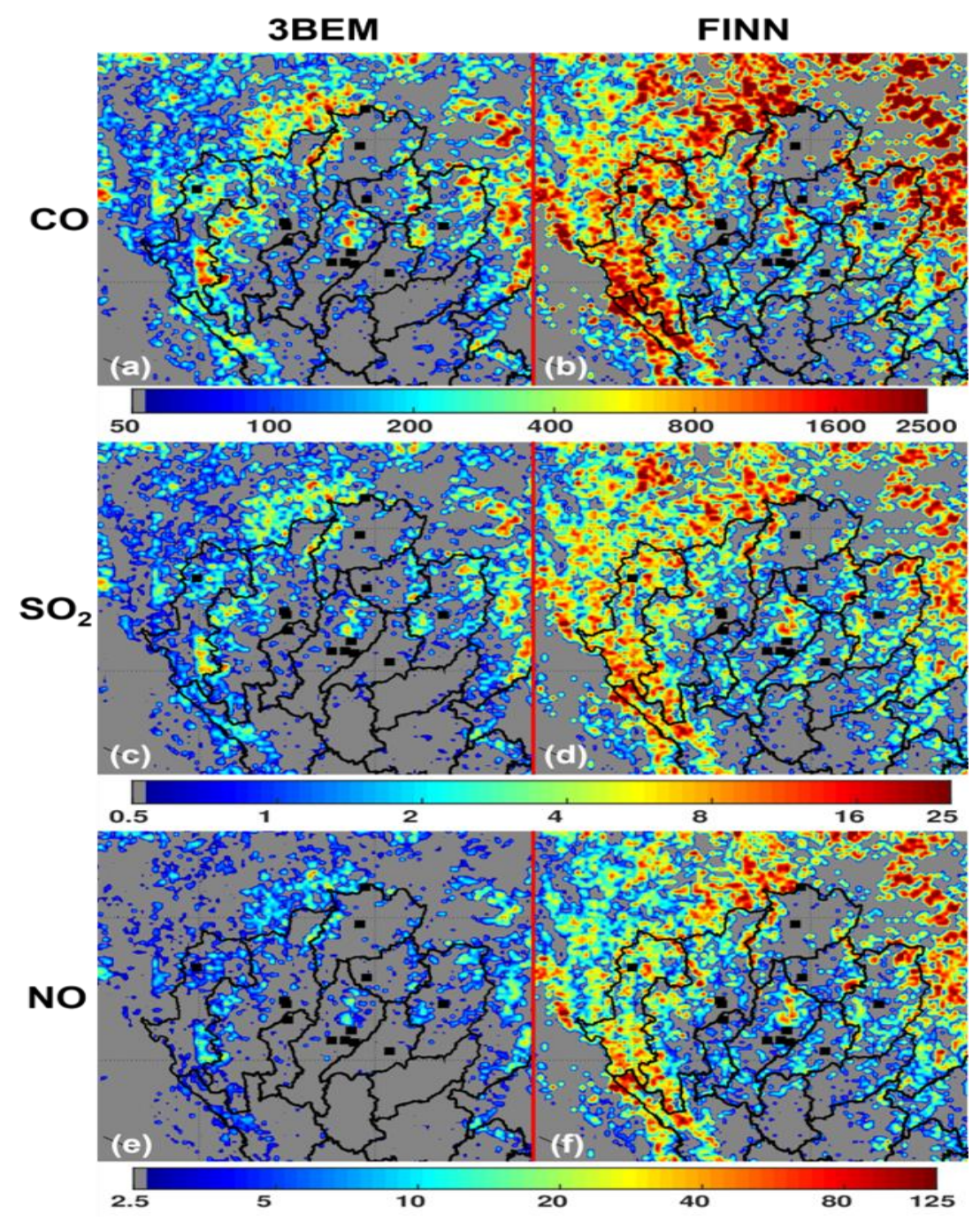

Figure 16. Comparisons of daily total 3BEM $(\mathbf{a}, \mathbf{c}, \mathbf{e})$ and $\operatorname{FINN}(\mathbf{b}, \mathbf{d}, \mathbf{f})$ emissions $\left(\mathrm{kg} \mathrm{m}^{-2}\right.$ day $\left.^{-1}\right)$ over the study area averaged over 31 days in March 2014. Top to bottom rows: $\mathrm{CO}, \mathrm{SO}_{2}$, and $\mathrm{NO}$ emissions, respectively. Black squares in each sub-figure show locations of ground stations employed in this study.

Figures 16 and 17 show that although the spatial patterns of 3BEM and FINN emissions are similar, FINN's emission amounts are significantly higher than those of 3BEM for all three emission species, particularly in the area surrounding the station T73. Table 10 shows the daily total 3BEM and FINN emissions $\left(\mathrm{kg} \mathrm{m}^{-2}\right.$ day $\left.^{-1}\right)$ of $\mathrm{CO}, \mathrm{SO}_{2}$, and $\mathrm{NO}$ averaged over the study area and over 31 days of March of 2014 and 2015. The results are consistent with those shown in Figures 16 and 17, that is, FINN significantly overestimates biomass burning emissions in the study area. The WRF-FINN significant overestimates of PM10 concentrations are hence clearly due to the FINN's overestimates of biomass burning emissions in the study area. 

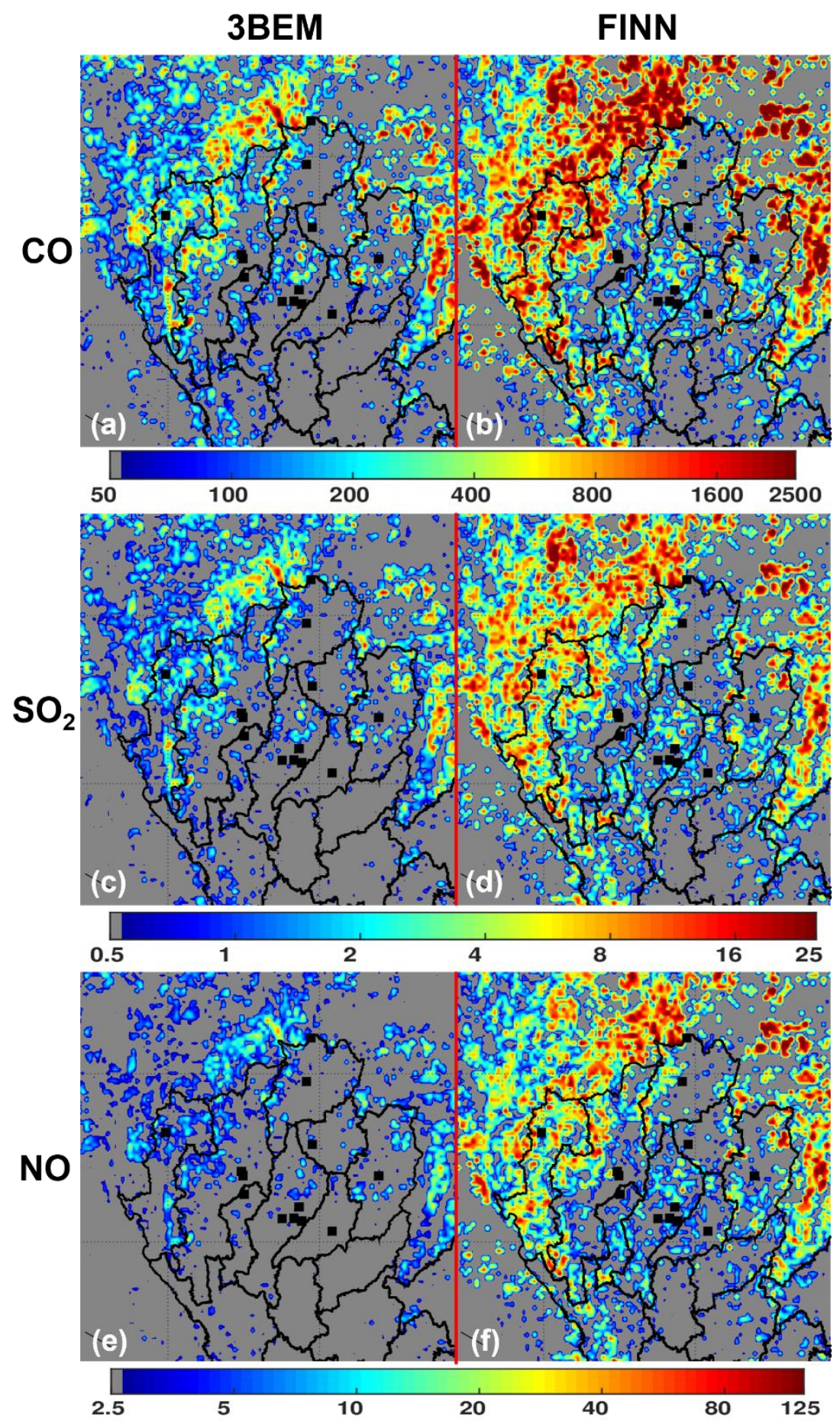

Figure 17. Comparisons of daily total 3BEM $(\mathbf{a}, \mathbf{c}, \mathbf{e})$ and FINN $(\mathbf{b}, \mathbf{d}, \mathbf{f})$ emissions $\left(\mathrm{kg} \mathrm{m}^{-2}\right.$ day $\left.^{-1}\right)$ over the study area averaged over 31 days in March 2015. Top to bottom rows: $\mathrm{CO}, \mathrm{SO}_{2}$, and $\mathrm{NO}$ emissions, respectively. The black squares in each sub-figure show the locations of ground stations employed in this study. 
Table 10. Daily total 3BEM and FINN emissions $\left(\mathrm{kg} \mathrm{m}^{-2}\right.$ day $\left.^{-1}\right)$ of $\mathrm{CO}, \mathrm{SO}_{2}$, and $\mathrm{NO}$ averaged over the study area and over 31 days in March of 2014 and 2015.

\begin{tabular}{ccccc}
\hline \multirow{2}{*}{ Emission Species } & \multicolumn{2}{c}{ March 2014 } & \multicolumn{2}{c}{ March 2015 } \\
\cline { 2 - 5 } & 3BEM & FINN & 3BEM & FINN \\
\hline $\mathrm{CO}$ & 154.06 & 498.15 & 133.08 & 440.06 \\
$\mathrm{SO}_{2}$ & 0.88 & 3.00 & 0.77 & 2.66 \\
$\mathrm{NO}$ & 2.14 & 12.88 & 1.83 & 11.30 \\
\hline
\end{tabular}

\section{Discussion and Conclusions}

A system for simulating the biomass burning aerosol transport at high resolution for the northern region of Thailand, which is in the tropics, is evaluated. The WRF-Chem model is employed to simulate biomass burning aerosol transport at $5 \mathrm{~km}$ resolution for the 3-month period covering from 1 February-30 April 2014 and 2015. The NCEP final analyses and the anthropogenic emission inventories from RETRO and EDGAR are employed. Biomass burning aerosol transport is simulated separately using two different biomass burning emissions inventories, i.e., 3BEM and FINN. PM10 dry mass concentrations are simulated using 3BEM (WRF-3BEM); those simulated using FINN (WRF-FINN), and their averages (WRF-AVG) are evaluated using hourly, daily, and monthly mean measurements from 12 and 13 ground stations for the years 2014 and 2015, respectively.

While the WRF-FINN and WRF-AVG simulations for hourly, daily, and monthly PM10 concentrations are significantly overestimated, the WRF-3BEM simulations agree well with the measurements. WRF-3BEM-simulated hourly, daily, and monthly PM10 concentrations are almost unbiased; that is, their MEs (E[simulations-measurements]) are $-0.54,-0.18$, and $-2.02 \mu \mathrm{g} \mathrm{m}^{-3}$, respectively. WRF-3BEM's monthly average PM10 concentrations-computed using all ground stations and for both years-are very close to that of measurements, i.e., $87.20 \mathrm{\mu g} \mathrm{m}^{-3}$ for WRF-3BEM and $89.22 \mu \mathrm{g} \mathrm{m}^{-3}$ for measurements, while those for WRF-FINN and WRF-AVG are 103.35 and 95.27 $\mu \mathrm{g} \mathrm{m}^{-3}$, respectively. RMSEs of WRF-3BEM simulations are also much lower than those of WRF-FINN and WRF-AVG simulations. RMSE of WRF-3BEM simulated hourly PM10 concentrations is 46.22 and $15.99 \%$ less than those of WRF-FINN and WRF-AVG, respectively. RMSE of WRF-3BEM simulated daily PM10 concentrations is 55.61 and 27.91\% lower than those of WRF-FINN and WRF-AVG, respectively. RMSE of WRF-3BEM simulated monthly PM10 concentrations is 72.00 and $47.01 \%$ less than those of WRF-FINN and WRF-AVG, respectively. WRF-3BEM simulations are well correlated with the measurements of CCs of 0.76 and 0.89 for the daily and monthly PM10 concentrations, respectively.

The reason for WRF-FINN's significant overestimates of PM10 concentrations in the study area is investigated by comparing the original 3BEM and FINN biomass burning emissions $\left(\mathrm{kg} \mathrm{m}^{-2}\right.$ day $\left.^{-1}\right)$ of $\mathrm{CO}, \mathrm{SO}_{2}$, and $\mathrm{NO}$. The comparisons show that FINN emissions are significantly higher than those of 3BEM, particularly over the areas surrounding the stations with high PM10 concentration errors. Since WRF-3BEM-simulated PM10 concentrations are in agreement with observations, FINN emissions are significantly overestimated over the northern region of Thailand. The WRF-FINN's significant overestimates of PM10 concentrations in the study are also consistent with the results presented by [8], which has shown that the monthly average PM10 concentration at $27 \mathrm{~km}$ resolution for the same 13 ground stations employed in this study with the addition of the Tap Mun station located in Hong Kong simulated using FINN is 2.18 times higher than that of measurements. Since [46] has previously shown that 3BEM's CO emissions are higher than those of FINN over Brazil, the same biomass burning emissions inventory can perform very differently for different areas. The biomass burning emissions inventory needs to be carefully selected to be appropriate for each study area.

The high-resolution biomass burning aerosol transport simulation system WRF-3BEM developed in this study performs much better than those developed in other previous studies for the same study area. WRF-3BEM is capable of providing useful high-resolution biomass burning aerosol transport simulations for the northern region of Thailand and will be an important tool for mitigating and 
solving the biomass burning emission impacts to the society. The simulation accuracy could be further improved by employing a higher resolution, and by using more accurate topographic data, land use data, tropospheric analyses, emission data, aerosol transport simulation models, and data assimilation techniques.

Author Contributions: Conceptualization, C.S.; methodology, C.S.; software, C.S., N., and T.N.; validation, C.S., N., and T.N.; formal analysis, C.S., N., and T.N.; investigation, C.S., N., and T.N.; resources, C.S.; data curation, N.; writing-original draft preparation, C.S. and N.; writing-review and editing, C.S., N., and T.N.; visualization, C.S., N., and T.N.; supervision, C.S.; project administration, C.S. All authors have read and agreed to the published version of the manuscript.

Funding: This research received no external funding.

Acknowledgments: This study was supported by the Interdisciplinary Graduate School of Earth System Science and Andaman Natural Disaster Management of the Prince of Songkla University, Phuket Campus, Thailand. The authors wish to thank the Pollution Control Department of Thailand for providing PM10 concentration measurements, the National Oceanic and Atmospheric Administration (NOAA) for making the anthropogenic emissions data publicly available at ftp://aftp.fsl.noaa.gov/divisions/taq/global_emissions/, the National Institute for Space Research (INPE) for providing the 3BEM biomass burning emission data, and the National Center for Atmospheric Research (NCAR) for making the FINN biomass burning emission data publicly available at http://bai.acom.ucar.edu/Data/fire/ and for making the NCEP final analyses publicly available at https://rda.ucar.edu. The authors would like to thank anonymous reviewers for the helpful comments and suggestions, which improve the paper.

Conflicts of Interest: The authors declare no conflict of interest.

\section{References}

1. Phairuang, W.; Hata, M.; Furuuchi, M. Influence of agricultural activities, forest fires and agro-industries on air quality in Thailand. J. Environ. Sci. 2017, 52, 85-97. [CrossRef]

2. Wiwanitkit, V. PM10 in the atmosphere and incidence of respiratory illness in Chiangmai during the smoggy pollution. Stoch. Environ. Res. Risk Assess. 2008, 22, 437-440. [CrossRef]

3. Wang, J.; Ge, C.; Yang, Z.; Hyer, E.; Reid, J.; Chew, B.N.; Mahmud, M.; Zhang, Y. Mesoscale modeling of smoke transport over the Southeast Asian Maritime Continent: Interplay of sea breeze, trade wind, typhoon, and topography. Atmos. Res. 2013, 122, 486-503. [CrossRef]

4. Lin, C.Y.; Zhao, C.; Liu, X.; Lin, N.; Chen, W. Modelling of long-range transport of Southeast Asia biomass-burning aerosols to Taiwan and their radiative forcing's over East Asia. Tellus B 2014, 66, 23733. [CrossRef]

5. Aouizerats, B.; Van der Werf, G.R.; Balasubramanian, R.; Betha, R. Importance of hgtransboundary transport of biomass burning emissions to regional air quality in Southeast Asia during a high fire event. Atmos. Chem. Phys. 2015, 15, 363-373. [CrossRef]

6. Oozeer, M.; Chan, A.; Ooi, M.C.G.; Zarzur, M.; Salinas, S.; Chew, B.N.; Morris, K.; Choong, W.K. Numerical Study of the Transport and Convective Mechanisms of Biomass Burning Haze in South-Southeast Asia. Aerosol Air Qual. Res. 2016, 16, 2950-2963. [CrossRef]

7. Shi, Y.; Matsunaga, T.; Saito, M.; Yamaguchi, Y.; Chen, X. Comparison of global inventories of $\mathrm{CO}_{2}$ emissions from biomass burning during 2002-2011 derived from multiple satellite products. Environ. Pollut. 2015, 206, 479-487. [CrossRef] [PubMed]

8. Vongruang, P.; Wongwises, P.; Pimonsree, S. Assessment of fire emission inventories for simulating particulate matter in Upper Southeast Asia using WRF-CMAQ. Atmos. Pollut. Res. 2017, 8, 921-929. [CrossRef]

9. Afrizal, T.; Surussavadee, C. High-Resolution Climate Simulations in the Tropics with Complex Terrain Employing the CESM/WRF Model. Adv. Meteorol. 2018, 15. [CrossRef]

10. Amnauylawjarurn, T.; Kreasuwun, J. Investigation of Fine and Coarse Particulate Matter from Burning Areas in Chiang Mai, Thailand using the WRF/CALPUFF. Chiang Mai J. Sci. 2012, 39, 311-326.

11. Nurzahziani; Surussavadee, C. Numerical simulations for biomass burning aerosol transport in northern Thailand. In Proceedings of the 2nd International Conference on Energy and Environmental Science, Kuala Lumpur, Malaysia, 16-18 January 2018. 
12. Longo, K.M.; Freitas, S.R.; Andreae, M.O.; Setzer, A.; Prins, E.; Artaxo, P. The Coupled Aerosol and Tracer Transport model to the Brazilian developments on the Regional Atmospheric Modeling System (CATT-BRAMS)-Part 2: Model sensitivity to the biomass burning inventories. Atmos. Chem. Phys. 2010, 10, 5785-5795. [CrossRef]

13. Archer-Nicholls, S.; Lowe, D.; Darbyshire, E.; Morgan, W.; Bela, M.; Pereira, G.; Trembath, J.; Kaiser, J.; Longo de Freitas, K.; Freitas, S.; et al. Characterising Brazilian biomass burning emissions using WRF-Chem with MOSAIC sectional aerosol. Geosci. Model. Dev. 2015, 8, 549-577. [CrossRef]

14. Zhong, M.; Saikawa, E.; Liu, Y.; Naik, V.; Horowitz, L.; Takigawa, M.; Zhao, Y.; Lin, N.; Stone, E.A. Air quality modeling with WRF-Chem v3.5 in East Asia: Sensitivity to emissions and evaluation of simulated air quality. Geosci. Model. Dev. 2016, 9, 1201-1218. [CrossRef]

15. Bossioli, E.; Tombrou, M.; Kalogiros, J.; Allan, J.; Bacak, A.; Bezantakos, S.; Biskos, G.; Coe, H.; Jones, B.; Kouvarakis, G.; et al. Atmospheric composition in the Eastern Mediterranean: Influence of biomass burning during summertime using the WRF-Chem model. Atmos. Environ. 2016, 132, 317-331. [CrossRef]

16. Wiedinmyer, C.; Akagi, S.; Yokelson, R.; Emmons, L.; Al-Saadi, J.; Orlando, J.; Soja, A. The Fire INventory from NCAR (FINN): A high resolution global, model to estimate the emissions from open burning. Geosci. Model. Dev. 2011, 4, 625-641. [CrossRef]

17. Loo, Y.Y.; Billa, L.; Singh, A. Effect of climate change on seasonal monsoon in Asia and its impact on the variability of monsoon rainfall in Southeast Asia. Geosci. Front. 2015, 6, 817-823. [CrossRef]

18. Justice, C.O.; Giglio, L.; Korontzi, S.; Morisette, J.T.; Roy, D.; Descloitres, J.; Alleaume, S.; Petitcolin, F.; Kaufman, Y. The MODIS fire products. Remote Sens. Environ. 2002, 83, 244-262. [CrossRef]

19. Giglio, L.; Schroeder, W.; Justice, C.O. The Collection 6 MODIS active fire detection algorithm and fire products. Remote Sens. Environ. 2016, 178, 31-41. [CrossRef]

20. World Health Organization (WHO). WHO Air Quality Guidelines for Particulate Matter, Ozone, Nitrogen Dioxide and Sulfur Dioxide: Summary of Risk Assessment; WHO/SDE/PHE/OEH/06.02; WHO: Geneva, Switzerland, 2006.

21. Ministry of Natural Resources and Environment. Booklet on Thailand State of Pollution 2018; No. 06-069; Pollution Control Department (PCD): Bangkok, Thailand, 2019; ISBN 978-616-316-511-4.

22. Skamarock, W.C.; Klemp, J.; Dudhia, J.; Gill, D.O.; Barker, D.; Wang, W. A Description of the Advanced Research WRF Version 3. NCAR Technical Note 2008; University Corporation for Atmospheric Research: Boulder, CO, USA, 2008; p. 113. [CrossRef]

23. Surussavadee, C.; Aonchart, P. Evaluation of WRF physics options for high-resolution weather forecasting in tropics using satellite passive millimeter-wave observations. In Proceedings of the IEEE International on Geoscience and Remote Sensing Symposium (IGARSS 2013), Melbourne, VIC, Australia, 21-26 July 2013; pp. 2262-2265.

24. Surussavadee, C. Evaluation of WRF Near-Surface Wind Simulations in Tropics Employing Different Planetary Boundary Layer Schemes. In Proceedings of the 8th International Renewable Energy Congress, Amman, Jordan, 21-23 March 2017.

25. Surussavadee, C. Evaluation of Tropical Near-Surface Wind Forecasts Using Ground Observations. In Proceedings of the 8th International Renewable Energy Congress, Amman, Jordan, 21-23 March 2017.

26. Grell, G.A.; Peckham, S.E.; Schmitz, R.; McKeen, S.A.; Frost, G.; Skamarock, W.; Eder, B. Fully coupled "online" chemistry within the WRF model. Atmos. Environ. 2005, 39, 6957-6975. [CrossRef]

27. Fast, J.; Gustafson, W.; Easter, R.; Zaveri, R.; Barnard, J.; Chapman, E.; Grell, G.; Peckham, S. Evolution of ozone, particulates, and aerosol direct radiative forcing in the vicinity of Houston using a fully coupled meteorology-chemistry-aerosol model. J. Geophys. Res. 2006, 111. [CrossRef]

28. Lim, K.S.S.; Hong, S.Y. Development of an effective double-moment cloud microphysics scheme with prognostic cloud condensation nuclei (CCN) for weather and climate models. Mon. Weather. Rev. 2010, 138, 1587-1612. [CrossRef]

29. Grell, G.A.; Devenyi, D. A generalized approach to parameterizing convection combining ensemble and data assimilation techniques. Geophys. Res. Lett. 2002, 29, 1693. [CrossRef]

30. Lee, S.W.; Lee, D.K.; Chang, D.E. Impact of horizontal resolution and cumulus parameterization scheme on the simulation of heavy rainfall events over the Korean Peninsula. Adv. Atmos. Sci. 2011, 28, 1-15. [CrossRef] 
31. Sun, X.; Barros, A.P. High resolution simulation of Tropical Storm Ivan (2004) in the southern Appalachians: Role of planetary boundary-layer schemes and cumulus parameterization. Q. J. R. Meteorol. Soc. 2014, 140, 1847-1865. [CrossRef]

32. Wootten, A.; Bowden, J.H.; Boyles, R.; Terando, A. The Sensitivity of WRF Downscaled Precipitation in Puerto Rico to Cumulus Parameterization and Interior Grid Nudging. J. Appl. Meteorol. Climatol. 2016, 55, 2263-2281. [CrossRef]

33. Bretherton, C.S.; Park, S. A new moist turbulence parameterization in the Community Atmosphere Model. J. Clim. 2009, 22, 3422-3448. [CrossRef]

34. Monin, A.S.; Obukhov, A.M. Basic laws of turbulent mixing in the surface layer of the atmosphere. Trudy Geofiz. Inst. 1954, 24, 163-187.

35. Chen, F.; Dudhia, J. Coupling an advanced land-surface/hydrology model with the Penn State/NCAR MM5 modeling system. Part I: Model description and implementation. Mon. Weather Rev. 2001, 129, 569-585. [CrossRef]

36. Surussavadee, C.; Staelin, D.H. Comparison of AMSU Millimeter-Wave Satellite Observations, MM5/TBSCAT Predicted Radiances, and Electromagnetic Models for Hydrometeors. IEEE Trans. Geosci. Remote Sens. 2006, 44, 2667-2678. [CrossRef]

37. Chin, M.; Rood, R.B.; Lin, S.J.; Muller, J.F.; Thomspon, A.M. Atmospheric sulfur cycle in the global model GOCART: Model description and global properties. J. Geophys. Res. 2000, 105, 24671-24687. [CrossRef]

38. Freitas, S.R.; Longo, K.M.; Alonso, M.F.; Pirre, M.; Marecal, V.; Grell, G.; Stockler, R.; Mello, R.F.; Gacita, M.S. PREP-CHEM-SRC 1.0: A preprocessor of trace gas and aerosol emission fields for regional and global atmospheric chemistry models. Geosci. Model. Dev. 2011, 4, 419-433. [CrossRef]

39. Schultz, M.G.; Leif, B.; Yves, B.; Bjoerndalsaeter, S.; Brand, R.; Burrows, J.P.; Dalsoeren, S.; Vasconcelos, M.; Grodtmann, B.; Hauglustaine, D.A.; et al. REanalysis of the TROpospheric Chemical Composition Over the Past 40 Years; European Geosciences Union: Hamburg, Germany, 2007.

40. Janssens-Maenhout, G.; Pagliari, V.; Guizzardi, D.; Muntean, M. Global Emission Inventories in the Emission Database for Global Atmospheric Research (EDGAR)_Manual (I). Gridding: EDGAR Emissions Distribution on Global Gridmaps; Publications Office of the European Union: Luxembourg, 2013.

41. Kaiser, J.W.; Heil, A.; Andreae, M.O.; Benedetti, A.; Chubarova, N.; Jones, L.; Morcrette, J.-J.; Razinger, M.; Schultz, M.G.; Suttie, M.; et al. Biomass burning emissions estimated with a global fire assimilation system based on observed fire radiative power. Earth Clim. 2012, 9, 527-554. [CrossRef]

42. Van der Werf, G.R.; Randerson, J.T.; Giglio, L.; Collatz, G.J.; Mu, M.; Kasibhatla, P.S.; Morton, D.C.; DeFries, R.S.; Jin, Y.; Van Leeuwen, T.T. Global fire emissions and the contribution of deforestation, savanna, forest, agricultural, and peat fires (1997-2009). Atmos. Chem. Phys. 2010, 10, 11707-11735. [CrossRef]

43. Prins, E.; Feltz, J.; Menzel, W.; Ward, D. An overview of GOES-8 diurnal fire and smoke results for SCAR-B and 1995 fire season in South America. J. Geophys. Res. 1998, 103, 31821-31835. [CrossRef]

44. Setzer, A.W.; Pereira, M.C. Amazonia biomass burnings in 1987 and an estimate of their tropospheric emissions. Ambio Stockh. 1991, 20, 19-22. [CrossRef]

45. UCAR. Fire Emission Factors and Emission Inventories. Available online: http://bai.acom.ucar.edu/Data/fire/ (accessed on 22 May 2018).

46. Pereira, G.; Siqueira, R.; Rosário, N.E.; Longo, K.L.; Freitas, S.R.; Cardozo, F.S.; Kaiser, J.W.; Wooster, M.J. Assessment of fire emission inventories during the South American Biomass Burning Analysis (SAMBBA) experiment. Atmos. Chem. Phys. 2016, 16, 6961-6975. [CrossRef]

(C) 2020 by the authors. Licensee MDPI, Basel, Switzerland. This article is an open access article distributed under the terms and conditions of the Creative Commons Attribution (CC BY) license (http://creativecommons.org/licenses/by/4.0/). 